\title{
The Impact of Childhood Intelligence on Later Life: Following Up the Scottish Mental Surveys of 1932 and 1947
}

\author{
Ian J. Deary, Martha C. Whiteman, and \\ John M. Starr \\ University of Edinburgh
}

\author{
Lawrence J. Whalley and Helen C. Fox \\ University of Aberdeen
}

\begin{abstract}
The Scottish Mental Surveys of 1932 and 1947 collected valid IQ-type test scores for almost everyone born in 1921 and 1936 and attending school on June $1,1932(N=89,498)$ and June 4, $1947(N=$ 70,805). These surveys are described. This research, using the surveys' data, examined (a) the stability of intelligence differences across the life span, (b) the determinants of cognitive change from childhood to old age, and (c) the impact of childhood intelligence on survival and health in old age. Surviving participants of the Scottish Mental Surveys were tested, and the surveys' data were linked with public and health records. Novel findings on the stability of IQ scores from age 11 to age 80; sex differences in cognitive aging; the dedifferentiation hypothesis of cognitive aging; and the effect of childhood IQ on all-cause and specific mortality, morbidity, and frailty in old age are presented.
\end{abstract}

Scotland's Mental Survey Committee gathered in 1931 to plan a study to describe the mental ability of the Scottish nation's children (Scottish Council for Research in Education, 1933). They found no practicable method of obtaining a representative sample. They decided to test the whole nation. On Wednesday, June 1, 1932, practically every child attending school in Scotland and born

Ian J. Deary and Martha C. Whiteman, Department of Psychology, University of Edinburgh, Edinburgh, Scotland; John M. Starr, Department of Geriatric Medicine, University of Edinburgh; Lawrence J. Whalley and Helen C. Fox, Department of Mental Health, University of Aberdeen, Aberdeen, Scotland.

Follow-up studies of the Scottish Mental Survey 1932 are a series of ongoing collaborations among the Department of Mental Health, University of Aberdeen; the Departments of Psychology, Universities of Edinburgh and Aberdeen; the Department of Radiology, University of Aberdeen; the Department of Clinical Neurosciences, University of Edinburgh; the Department of Biophysics and Bioengineering, University of Aberdeen; the Scottish Council for Research in Education; and the Department of Geriatric Medicine, University of Edinburgh. The present new analyses were supported by two grants from the Biotechnology and Biological Sciences Research Council and grants from the Medical Research Council, Scottish Executive Health Department's Chief Scientist Office, and the Wellcome Trust. Ian J. Deary is the recipient of a Royal Society-Wolfson Research Merit Award. Lawrence J. Whalley holds a Wellcome Trust Career Development Award.

We thank Valerie Wilson and Graham Thorpe (Scottish Council for Research in Education) for providing access to age-11 Moray House Test scores from the Scottish Mental Surveys of 1932 and 1947. We thank Steven Leaper, Helen Lemmon, Alison Pattie, Mariesha Struth, and nurses at the Wellcome Trust Clinical Research Facility, Western General Hospital, Edinburgh, for assisting in the collection of data, and John R. Crawford for advice and training on the psychometric tests. We thank Kevin Pearson and James Boyd for linking Scottish Mental Survey data to health and public records.

Correspondence concerning this article should be addressed to Ian J. Deary, Department of Psychology, University of Edinburgh, 7 George Square, Edinburgh EH8 9JZ, Scotland. E-mail: i.deary@ed.ac.uk in 1921 took the same mental test with the same time limit after hearing the same instructions. Thus Scotland was and remains the only nation with mental test data for almost an entire birth cohort. What is more, they repeated the exercise in 1947, testing almost all people born in 1936 (Scottish Council for Research in Education, 1949).

The Mental Survey Committee decided to use a version of one of the Moray House Tests devised by Godfrey Thomson, one of the committee members (Scottish Council for Research in Education, 1933). Thomson chaired the committee that organized the later mental survey in 1947. The Moray House Tests were used in the United Kingdom for selection from primary to secondary school education at about age 11 years. Children with better scores were channeled into a more academic educational program. The devising, by Thomson, of such tests for these educational purposes is remarkable. Thomson is well known to researchers in intelligence as a decades-long opponent of Spearman's general factor theory of intelligence (Thomson, 1939). He conceived an alternative model of intellectual function in which many separate cognitive bonds were said to account for the universal positive associations among mental tests just as well as Spearman's general factor $(g)$. Therefore, it is surprising to find Thomson being so involved with a process that involved a mental test with a single score. Moreover, Thomson was ideologically opposed to school selection. Yet, he was intimately involved with the large-scale application of the Moray House Tests that used mental test scores to select children for secondary education. Sharp (1997) reckoned that despite these tensions, Thomson had concluded that British education was better with test-based selection than without, because it afforded an opportunity for children from humble backgrounds (like Thomson himself) to receive an otherwise unavailable academic education.

The Scottish Council for Research in Education (SCRE) gathered three data sets concerning the mental ability of 11-year-olds in Scotland. Two of these gathered data on entire year-of-birth cohorts. The third, conducted between these two, was smaller $(N=$ 
874) and is not discussed further (MacMeeken, 1939). This article describes the Scottish Mental Surveys of 1932 and 1947, discusses our research that follows up these surveys, and presents several new analyses based on these data.

\section{The Scottish Mental Survey 1932}

The Scottish Mental Survey 1932 (SMS1932) aimed to test the mental ability of all people born in 1921 and attending Scottish schools on June 1, 1932 (some, in fact, were tested a few days later; Scottish Council for Research in Education, 1933). The objectives of the study were (a) to discover the rates of mental deficiency following an earlier study in England and Wales and (b) to obtain information about the distribution of intelligence throughout the community. Later, these aims were seen as naive, because the group test used (originally the Moray House Test No. 12; referred to as the Verbal Test in the SMS1932) was designed to separate out those suited to a grammar school education. A few private schools did not take part in the SMS1932, and we have since discovered other small-scale omissions, such as individual schools that did not receive test papers and others that received too few. Test data were obtained for 87,498 children: 44,210 boys and 43,288 girls. The Moray House Test No. 12 had 71 items, including the following:

5. If $19 \mathrm{~d}$ is the same as $1 / 7$ write $\mathrm{G}$, if not write $\mathrm{R}$.

12. Fin is to fish as wing is to [feather, air, bird, sail, herring].

36. "Tragu" is cheaper than "vashol," and "vashol" is dearer than "spongop." Which is the dearest?

42. Underline the "different" word in [eye, pen, nose, chin, ear].

58. Three posts are at the corners of an equilateral, that is an equalsided, triangle. From where I am standing, the post nearest to me seems to be exactly half-way between the other two. If I now take two sidesteps to the left, will the posts look like:

this I I I or like this I I I?

The test has a variety of types of items: following directions (14 items), same-opposites (11), word classification (10), analogies (8), practical items (6), reasoning (5), proverbs (4), arithmetic (4), spatial items (4), mixed sentences (3), cypher decoding (2), and other items (4).

A score of 76 was the maximum possible in the Moray House Test. Eight practice items preceded the test. There were two short picture tests also, designed for the children who found the Moray House Test too difficult. These latter tests had ceiling effects and were not analyzed much thereafter. As late as the 1960s it was claimed that Scotland "remains the only country with records of intelligence test scores of a complete age group of school children" (Maxwell, 1961, p. 14).

The Moray House Test did not give IQ estimates. Therefore, in the summer following the SMS1932, a subsample of 1,000 pupils was given the Stanford Revision of the Binet Scale (often referred to as the Binet 1,000). The attempt was to make this 1,000 as representative of the Scottish 11-year-old population as possible, by sampling all educational areas. Children born at or near June 1 were tested. In the end, 847 who were tested on the Binet were born in June, 101 in May, and the rest in April and July. However, the Binet boys $(n=500)$ scored 4 points higher on average than the population on the group test, and the Binet girls $(n=500)$ scored 2.5 points higher. The Moray House Test correlated about .8 (.81 in the boys, .78 in the girls) with Stanford-Binet scores, providing criterion validity for the Moray House Test (Scottish Council for Research in Education, 1933, p. 100).

\section{The Scottish Mental Survey 1947}

The motivation for this study was the concern that the mean IQ of the nation was falling, because people in larger families were thought to have lower average IQs than those in smaller families (Scottish Council for Research in Education, 1949). The United Kingdom's Population Investigation Committee of the Royal Commission on Population took advantage of the fact that all 11-year-olds in Scotland had been tested 15 years previously and asked for the notion of declining national IQ to be tested by the SCRE. The Scottish Mental Survey 1947 (SMS1947) was funded by the Population Investigation Committee, the Eugenics Society, the Nuffield Foundation, and the Rockefeller Foundation. The SMS1947 results produced "the apparent paradox of the rise in group scores between 1932 and 1947 and the fall in intelligence suggested by the indirect calculations of Burt, Cattell and Thomson" (Scottish Council for Research in Education, 1949, p. 147). This is one of the earliest and certainly the most comprehensive demonstration of the Flynn (1999) effect on IQ-type test scores. The Flynn effect is the finding that scores on the same tests rose in subsequent generations during the 20th century. Its cause or causes remain unknown.

On June 4, 1947, almost all 1936-born children attending Scottish schools were given the same Moray House Test as was used in 1932, with the same instructions and time limit. For each pupil, the number of siblings and position in the family were recorded. The SMS1947 provides arguably the most comprehensive available data showing that children from larger families have lower mean IQ scores. (Figure 1 was compiled from the SMS1947 data; Maxwell, 1961, p. 25.)

The survey tested 70,805 of the 75,211 people born in 1936 . For those tested in the SMS1947, the following information was obtained for this whole sample: education authority area; location of school: city, large town, small town, other; size of school; number of full-time teachers on school staff; location of home (as for school); class in school; date of birth; sex; location of child's birthplace; position in and size of family; twin or not; brother and sister also born in 1936; attendance during session; number of schools previously attended; survey group intelligence test score (Moray House Test score).

\section{The 36-Day Sample of the SMS1947}

The people born on the first 3 days of each month were used as a subsample to gain more information. The following extra information was obtained for these people: evacuation during World War II; living with own mother or not; occupation of father or guardian; age of mother; number of persons per room in home; height of pupil; weight of pupil; certain specified disabilities (e.g., visual defect, paralysis, or epilepsy).

The sample with these data were called the random sample sociological schedule. The above data were also gathered for all twins (525 pairs). 


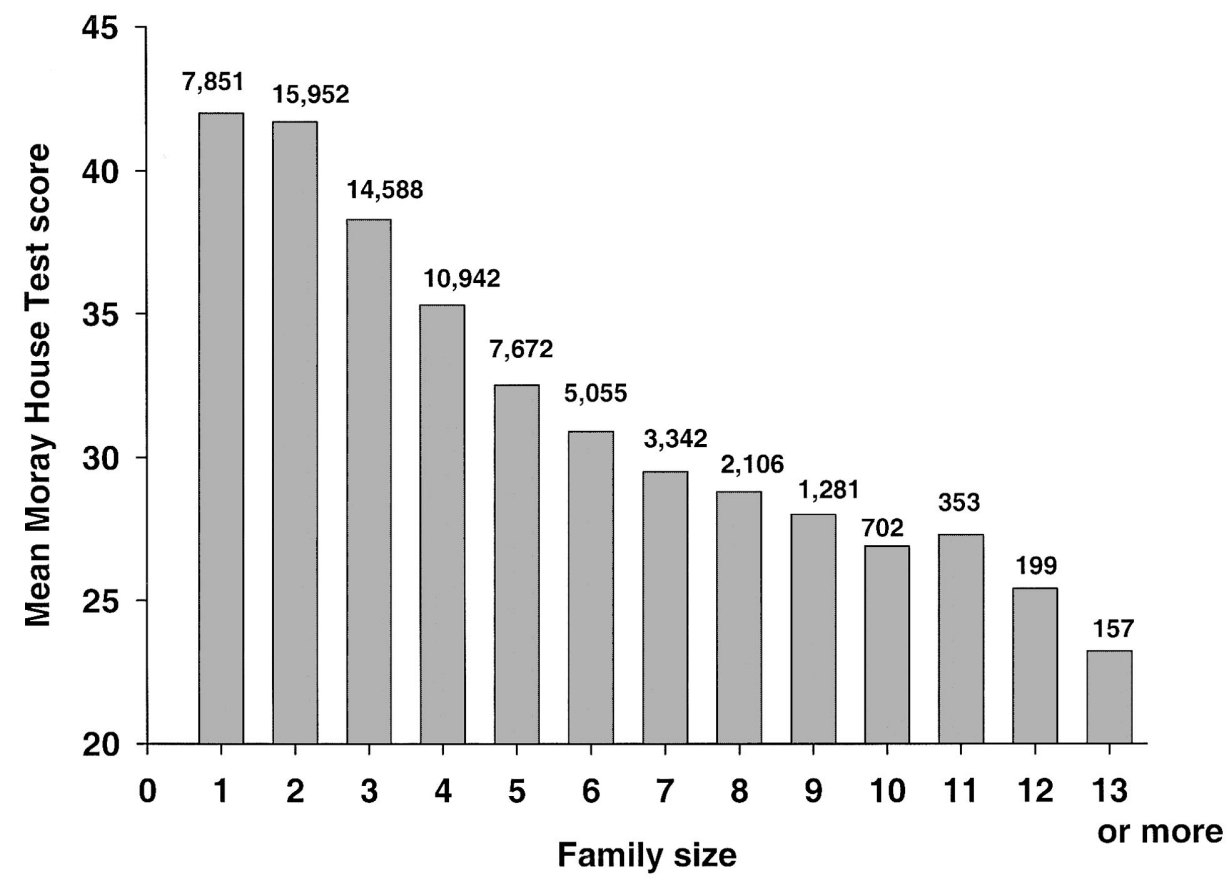

Figure 1. Association between mean Moray House Test score in the 1947 Scottish Mental Survey and family size (number of children). Numbers at the top of each bar indicate the number of participants in each category.

\section{The 6-Day Sample of the SMS1947}

The 6-day sample of the SMS1947 comprised people born on the 1st day of alternative months of 1936, from February onward $(n=1,208)$. The same data were gathered as for the 36-day sample. They took an additional, individual IQ-type test: the Terman-Merrill 1937 Revision (Form L) of the Binet Test. These tests were completed during the summer of 1947. The 36- and 6-day samples were highly representative of the whole sample. Detailed home, occupational, and recreational information was gathered from the 6-day sample for the next 16 years (MacPherson, 1958; Maxwell, 1969). Each of the 6-day sample's participants was visited at home once a year by a researcher. Also, their younger siblings were tested on the individual IQ-type test as they reached the age of 11 years. The social background determinants of psychometric intelligence and the influences of psychometric intelligence, education, and social class on aspects of life up to the mid-20s are described for the 6-day sample in a number of research monographs (MacPherson, 1958; Maxwell, 1961, 1969; Scottish Council for Research in Education, 1958).

\section{Planning Follow-Up Studies of the SMS1932 and SMS1947}

\section{Uses of the SMS1932 and SMS1947: Cohort Follow-Up and Database Linkage Studies}

Data for two entire year-of-birth cohorts in our nation were clearly a remarkable resource, but little could be done with the data alone. Whereas most research teams formulate hypotheses and then seek the relevant resources, we had access to unique data and felt the responsibility to conceive hypotheses that they might test.
The importance of the Scottish Mental Surveys' data lay in our tying individual cognitive test scores from age 11 to other information about these participants. A research program was conceived as follows.

First, the data were a unique opportunity to study cognitive aging - the stability and determinants of change in mental functioning - over the human life span. Cognitive aging is recognized internationally as a research priority (Fillit et al., 2002; National Research Council, 2000). We had collaborated previously on cognitive aging research (Deary, Starr, \& MacLennan, 1999; Starr, Deary, Inch, Cross, \& MacLennan, 1997; Starr, Deary, \& Whalley, 1996). However, few studies possess cognitive information from older participants' youth to allow actual cognitive change to be measured. Those very few studies that do possess such data are based on smaller, unrepresentative, single-sex groups, and some have relatively poor cognitive data (e.g., Owens, 1966; Plassman et al., 1995; Pushkar Gold et al., 1995; Snowdon et al., 1996). Therefore, we were in a position to begin to estimate the stability in human intelligence from age 11 to almost 80 and to discover the determinants of cognitive change between those ages. To execute this part of the research program, we needed to trace, recruit, and test individuals who had originally taken the Moray House Test in the SMS1932 and SMS1947. Some of this work is presented below, with some new analyses undertaken for this report.

Second, the data from the Scottish Mental Surveys of 1932 and 1947 were an opportunity to explore the importance of mental ability in youth as a determinant of health and quality of life in old age. Whereas many studies had examined the predictive value of parental social class and education on mortality and morbidity in later life (e.g., Davey Smith, Hart, Blane, \& Hole, 1998; Davey Smith, Hart, Hole, et al., 1998; Kunst \& Mackenbach, 1994), no 
population-based studies had access to mental test data in youth (see Whalley \& Deary, 2001). This part of the research program was executed in two ways: by recruiting survivors from the original survey and by linking the mental test data to the especially rich and comprehensive public and health records in Scotland and the rest of the United Kingdom. We now describe the resources available for such database linkage studies before proceeding in detail to describe the recruitment of samples of surviving members of the Scottish Mental Surveys.

Using name and date-of-birth data, we linked individuals who took part in the SMS1932 and SMS1947 to public, health, and other records in Scotland and the United Kingdom. The Registrar General's Office holds records of births, marriages, and deaths for Scotland and has a link to the same records for the rest of the United Kingdom. The Information and Statistics Division of the National Health Service Scotland holds computerized records of all hospital discharges (with International Classification of Diseases [ICD]-coded diagnoses), cancer registrations, and hospital admissions for mental illness from 1968 to the present day. The Lothian Health Archive at the University of Edinburgh contains details of births (including birth weight and length and information about the mother) in Edinburgh hospitals that include the year 1921.

\section{Recruiting the ABC1921, LBC1921, and ABC1936 Cohorts}

Since 1997 and 1999, respectively, survivors of the SMS1932 were recruited from the Aberdeen and Edinburgh areas of Scotland. Aberdeen-centered recruitment of SMS1947 participants began in 1999. General publicity and some recruitment were done using print and broadcast media (radio, television, and newspapers). More targeted recruitment used the United Kingdom's Community Health Indices. These are area-based lists of people's registration with a general medical practitioner. Because of the United Kingdom's National Health Service, more than $99 \%$ of the Scottish population appears on such a list. We obtained permission from area health boards to identify people on the Aberdeen- and Edinburgh-area lists who were born in 1921 and 1936. On our request, general medical practitioners wrote to those individuals who were living independently in the community and were relatively healthy and invited them to take part in our research program to follow up the SMS1932 and SMS1947. Using these procedures, we recruited and tested 234 people in the Aberdeen area (the Aberdeen Birth Cohort of 1921 [ABC1921]) and 550 people in the Edinburgh area (the Lothian Birth Cohort 1921 [LBC1921]) who were born in 1921. Many of the individuals in the ABC1921 have been followed up twice more since their original visit to our centers. To date, over 400 people born in 1947 have been recruited from the Aberdeen area (the Aberdeen Birth Cohort 1936 [ABC1936]). All participants took part in a half-daylong assessment that included the collection of psychological, social, medical, and physiological data. Blood was taken for biochemical, hematological, endocrine, lipid, and other analyses and for DNA extraction. Some of the ABC1921 participants underwent magnetic resonance imaging of the brain (Deary, Leaper, Murray, Staff, \& Whalley, 2003; Leaper et al., 2001).

The details of the ABC1921 participants, methods, and procedures have been the subject of a number of our published reports
(Crawford, Deary, Starr, \& Whalley, 2001; Deary, Leaper, et al., 2003; Deary, Whalley, Lemmon, Crawford, \& Starr, 2000; Duthie et al., 2002; Leaper et al., 2001; Starr, Deary, Lemmon, \& Whalley, 2000), and we do not repeat them here. The ABC1936 participants took the same tests as did the ABC1921 participants. The present article includes some of the first published data analyses from the LBC1921, with the exception of a brief report (Deary et al., 2002); therefore the details of tracing, recruiting, and testing this cohort are now described. The LBC1921 recruitment procedures and measures are very similar to those in the ABC1921; some differences in the mental tests used in the two centers are noted below.

\section{LBC1921 Study}

\section{Participants}

The SMS1932 data are kept in area-based, handwritten ledgers in Edinburgh at the Scottish Council for Research in Education. The pupils' Moray House Test scores are recorded within schools, in order of their dates of birth. Before LBC1921 study recruitment began (in 1999), the Edinburgh and Lothian ledgers were transcribed into a computer database. To construct the LBC1921, we searched for SMS1932 survivors by identifying people in the Edinburgh area who were born in 1921 and asking them if they had attended school in Scotland in 1932. We searched for 1921-born people in two ways: (a) via the Community Health Index (CHI) for Edinburgh and its surrounding area (Lothian region) and (b) through advertisements placed in local, regional, and national newspapers. From the advertisements, 423 people telephoned for further information. Of these, $368(86.9 \%)$ fulfilled study criteria, and $321(87.2 \%)$ of the eligible sample agreed to take part. On the basis of the $\mathrm{CHI}$ information, local doctors sent leaflets on our behalf to 1,120 people. Of these, $728(59.6 \%)$ replied, with 501 (68.8\% of replies) fulfilling study criteria. Of the eligible 501 people, $260(51.8 \%)$ took part in the study. In all, 550 (234 men, 316 women) ambulant, independent participants were recruited and tested, and they constitute the LBC1921.

\section{Method}

\section{Cognitive Tests}

Moray House Test. This is the general mental ability test that participants took at age 11, in 1932 (Deary et al., 2000; Scottish Council for Research in Education, 1933). Two items were altered slightly because of changes in usage that might have caused confusion. Instructions and the time limit were also kept the same as in the original test. (The ABC1921 and ABC1936 participants undertook the Block Design and Digit Symbol subtests of the Wechsler Adult Intelligence Scale-Revised instead of the Moray House Test; Wechsler, 1981.)

Mini-Mental State Examination. This screens for dementia (Folstein, Folstein, \& McHugh, 1975). The maximum score is 30; scores of less than 24 are used by some researchers and clinicians to indicate possible dementia.

Logical Memory. This is from the Wechsler Memory Scale-Revised (Wechsler, 1987). Two short stories containing 25 memory items each are read aloud. Immediately after each, the participant is asked to tell the interviewer as much as they remember about it. After a minimum of 30 minutes' delay, participants are again asked to recall as much as they can about the stories. (Participants in the ABC1921 and ABC1936 took the Auditory Verbal Learning Test instead of this test; Lezak, 1995.) 
Raven's Progressive Matrices. This 60-item test measures nonverbal reasoning ability (Raven, Court, \& Raven, 1977). Participants are shown an incomplete pattern and asked to choose the correct item (from several alternatives) to complete the pattern.

National Adult Reading Test (NART). The NART assesses premorbid or prior cognitive ability (Crawford et al., 2001; Nelson, 1982; Nelson \& Willison, 1991). The test requires the participant to pronounce 50 irregular words.

Verbal fluency. This task is said to assess executive function (Lezak, 1995). The participant is asked to name as many words as possible beginning with the letters $C, F$, and $L$ and is given $1 \mathrm{~min}$ for each letter. Proper names are not allowed, and repeated words are scored only once. (The ABC1921 and ABC1936 participants undertook Uses of Common Objects instead of this test; Lezak, 1995.)

Hospital Anxiety Depression Scale. This scale contains seven items for anxiety and seven items for depression (Zigmond \& Snaith, 1983). The maximum score on each scale is 21 , with probable anxiety or depression at scores of 11 or over.

\section{Physical Tests}

The purpose of the physical tests was to obtain markers of health and fitness. The test battery comprised the following assessments: height, weight, and demi-span (distance from the sternal notch to the web of skin between the second and third fingers); visual acuity; time to walk 6 meters; blood for biochemical and rheological factors; blood for DNA extraction for later identification of genotypes such as the apolipoprotein $\mathrm{E}$ gene (APOE; Deary, Whalley, et al., 2003; Deary, Whiteman, et al., 2002; MacLullich, Seckl, Starr, \& Deary, 1998); lung function (peak flow, forced vital capacity, forced expiratory volume, and forced expiratory rate); blood pressure; grip strength; and resting, 12-lead electrocardiogram.

The Townsend Disability Scale (Bond \& Carstairs, 1982; Townsend, 1979) was administered. Scores of 0 (no difficulty), 1 (some difficulty), or 2 (unable to do) were recorded for a series of 14 questions such as "Are you able to: cut your own toe-nails? to wash all over or bathe? to shop and carry heavy bags?"

\section{Procedure}

LBC1921 participants were tested at the Wellcome Trust Clinical Research Facility at the Western General Hospital, Edinburgh. Two nurses were specially trained to carry out the physical testing of the participants. Trained researchers carried out cognitive testing and interviewing. Testing took place from September 1999 until July 2001. Each appointment lasted approximately $3 \mathrm{hr}$ and contained one tea break and lunch. All testing was carried out on an individual basis.

Participants were first interviewed about their medical history, educational and employment history, and smoking and alcohol consumption. The Mini-Mental State Examination was administered next, followed by the first reading of the Logical Memory stories from the Wechsler Memory Scale-Revised. Participants then took the Moray House Test (the whole first session lasted about $1 \mathrm{hr}$, with exactly 45 min allocated for the Moray House Test). The tea break was next $(20 \mathrm{~min})$, followed by the physical testing (40-45 $\mathrm{min})$. The final session comprised three further cognitive tests $(30 \mathrm{~min})$. The order of physical tests and final cognitive session was sometimes reversed to facilitate testing of a few participants simultaneously.

\section{Results}

\section{SMS1932 and SMS1947: Contributions to Psychometric Intelligence}

Stability from age 11 to age 80 in the LBC1921. Our first follow-up study of the SMS1932 examined the stability of Moray
House Test scores in the ABC1921 from age 11 to age about 77 in 101 relatively healthy participants in the Aberdeen area (Deary et al., 2000). The stability coefficient of Moray House Test scores between 1932 and 1998 was $.63(p<.001)$, which became .73 after disattenuation for restriction of the variance in the sample. The testing of the LBC1921 then allowed us to replicate and extend these findings on a sample almost five times larger and to offer robust estimates of stability in men and women separately. Retesting the SMS1932 participants extended, by over 2 decades, the period between test and follow-up of the previously longest studies in the field (Owens, 1966; Pushkar Gold et al., 1995). These data are reported here for the first time.

Descriptive data for Moray House Test scores and Raven's Progressive Matrices test scores for the LBC1921 are shown in Table 1. The concurrent validity of the Moray House Test scores is displayed in Table 1 and Figure 2. Participants' Moray House Test scores correlated about .8 with Stanford-Binet test scores in 1,000 11-year-old children (500 boys, 500 girls) tested individually, who constituted a reasonably representative sample of the SMS1932. Deary et al. (2000) reported a correlation of .57 between Moray House Test scores at about age 80 years and scores on Raven's Standard Progressive Matrices. In the LBC1921, 541 participants provided Moray House Test and Raven data at about age 80 . They correlated .71, with identical correlations in men and women. Therefore, the Moray House Test has good concurrent validity when tested against general mental ability tests at age 11 and age about 80 years.

The stability of Moray House Test scores in the LBC1921 from age 11 to age about 80 is shown in Table 1 and in Figures 2 and 3 . In the whole Lothian birth cohort sample, the Pearson $r$ stability coefficient is $.66\left(r_{\mathrm{s}}=.66\right)$, with values of $.62\left(r_{\mathrm{s}}=.65\right)$ for men and $.69\left(r_{\mathrm{s}}=.67\right)$ for women. The respective values for the ABC1921 were .63, .62, and .67 (Deary et al., 2000). The present LBC1921 sample is about fivefold larger than the ABC1921 sample on which our previous report was based.

Table 1

Descriptive Statistics of, and Correlations Among, Mental Tests for Participants in the Lothian Birth Cohort 1921

\begin{tabular}{lrrrrr}
\hline \multicolumn{1}{c}{ Variable } & $M$ & \multicolumn{1}{c}{$S D$} & $n$ & MHT age 11 & MHT age 80 \\
\hline \multicolumn{7}{c}{ All participants } \\
MHT age 11 & 46.4 & 11.9 & 493 & - & \\
MHT age 80 & 59.2 & 10.8 & 542 & .66 & - \\
Raven & 31.2 & 8.8 & 543 & .45 & .71 \\
\hline \multicolumn{7}{c}{ Men } \\
MHT age 11 & 46.0 & 12.7 & 208 & - & \\
MHT age 80 & 60.5 & 10.6 & 229 & .62 & -74 \\
Raven & 32.6 & 8.7 & 230 & .44 & .71 \\
\hline & & & Women & & \\
MHT age 11 & 46.7 & 11.6 & 285 & - & \\
MHT age 80 & 58.3 & 10.9 & 313 & .69 & -71 \\
Raven & 30.1 & 8.7 & 313 & .48 & \\
\hline
\end{tabular}

Note. $\quad$ MHT $=$ Moray House Test $;$ Raven $=$ Raven's Standard Progressive Matrices. For all correlations, $p<.001$. 


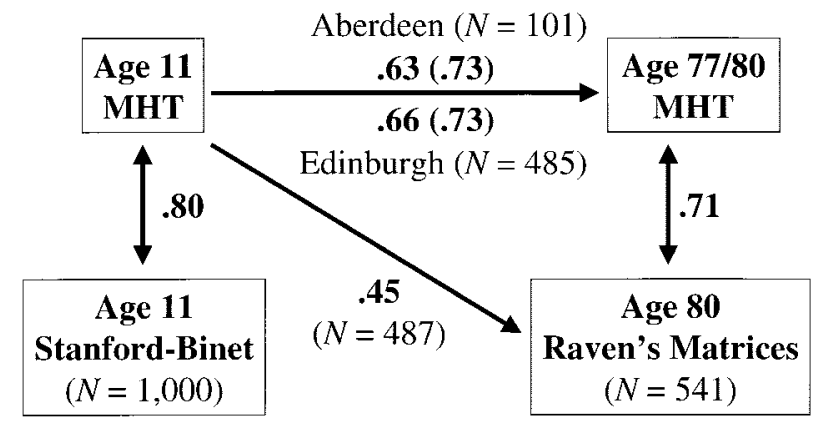

Figure 2. The concurrent validity and stability of raw Moray House Test (MHT) scores from age 11 to age 80. Coefficients in parentheses are disattenuated for restriction of range in the samples.

LBC1921 is restricted in range by comparison with the SMS1932 population (Maxwell, 1961, p. 22). Disattenuating the correlations between Moray House Test scores at age 11 and age about 80 years for this restriction of ability range gives the following coefficients: For all participants, $r=.73$; for men, $r=.71$; for women, $r=.78$. The disattenuated value of .73 in the LBC1921 is the same as the disattenuated value in the ABC1921 (Deary et al., 2000). These disattenuated coefficients are still underestimates of the true stability of Moray House Test scores from age 11 to about age 80 . They are based on the assumption that the reliable variance in Moray House Test scores is 1.0. Instead, a better estimate of the reliable variance would be the short-term test-retest correlation of the Moray House Test scores. Assuming a short-term test-retest correlation of about .9, the true stability of the Moray House Test scores from age 11 to age 80 might be as high as .8.

These analyses were based on raw scores. The raw Moray House Test scores were then age corrected and converted to IQ-type scores $(M=100 ; S D=15)$ for the purposes of the scattergram shown as Figure 3 . The age 11-age 80 stability coefficient for these scores is .66, the same value as that obtained using raw scores. Age-corrected age-11 Moray House Test IQ scores were regressed on age-80 Moray House Test IQ scores. The linear effect accounted for $43.4 \%$ of the variance, and the quadratic effect, although significant $(p<.001)$, added only a further $0.3 \%$ of the variance.

In summary, the present examination of the LBC1921 of the SMS1932 provides, as far as we are aware, the longest follow-up study of the stability of mental ability differences in the literature (cf. Kangas \& Bradway, 1971; Owens, 1966; Plassman et al., 1995; Pushkar Gold et al., 1995). The stability coefficient and concurrent validity results of the fivefold smaller ABC1921 are confirmed (Deary et al., 2000). This is an important result to establish, because the current, intense interest in discovering the determinants of age-related cognitive change (Anstey \& Christensen, 2000; Fillit et al., 2002; National Research Council, 2000) must first be informed by the basic stability that exists in psychometric intelligence across the life span.

Intelligence and the dedifferentiation hypothesis: ABC1921 and $A B C 1936$. The notion that the $g$ factor becomes stronger with age has been mooted often but has, as yet, limited evidence (Deary et al., 1996, review this area; Baltes \& Lindenberger, 1997; Lienert
\& Crott, 1964). The Aberdeen Birth Cohorts of 1921 and 1936 provide a rare opportunity to examine this dedifferentiation hypothesis of cognitive aging. They provide 74 people born in 1921 (49 men, 25 women) and 353 people born in 1936 (179 men, 174 women) with the following unique characteristics: Both samples took the same Moray House Test at the same age (11 years) and under the same testing conditions, 15 years apart; both samples took the same battery of cognitive tests in the late 1990s in the same research center using the same procedures; and both samples are taken from a population year-of-birth cohort that was tested at age 11 in its entirety, which means that any sampling restrictions are known precisely. These data are examined here for the first time.

The main focus of interest for these data were the correlations among test scores. However, the means were examined also (see Table 2). Crucially, for examining the dedifferentiation hypothesis, the ABC1921 and ABC1936 samples had very similar means and standard deviations for their Moray House Test age-11 scores (Table 2). Raven, Block Design, Digit Symbol, Uses of Objects, and Auditory Verbal Learning Test (AVLT) scores were outcomes in a multivariate analysis of covariance, with Moray House Test age-11 score as a covariate and sex and cohort as between-subjects effects. The multivariate effects of Moray House Test score at age $11, F(5,418)=50.4, p<.001$, partial $\eta^{2}=.38$; cohort, $F(5$, $418)=34.1, p<.001$, partial $\eta^{2}=.29$; and sex, $F(5,418)=10.8$, $p<.001$, partial $\eta^{2}=.11$; were significant. There was no significant Sex $\times$ Cohort interaction, $F(5,418)=1.1, p=.37$, partial $\eta^{2}=.01$. Univariate tests showed that the younger cohort had significantly better test scores on all but the Uses of Objects test. Men scored significantly higher on Raven and Block Design, whereas women scored higher on Uses of Objects and AVLT.

It is widely accepted that two ways of examining the dedifferentiation hypothesis of cognitive aging are to examine (a) the relative correlation coefficients among test scores in different age groups and (b) the proportion of variance accounted for by the first unrotated principal component (the general, or $g$, factor) from a principal components analysis of the test scores (Deary et al.,

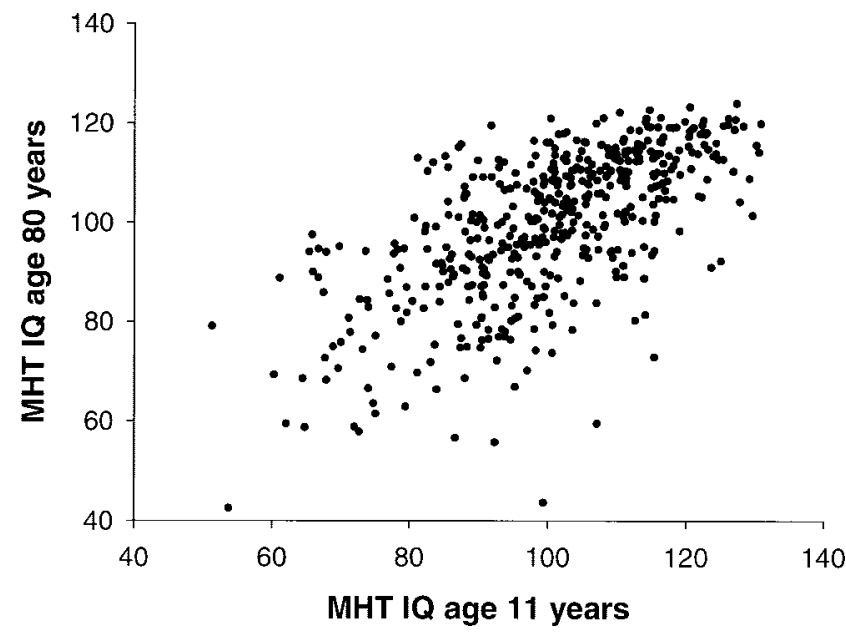

Figure 3. Scattergram of age-corrected Moray House Test (MHT) scores at age 11 and age 80 for participants in the Lothian Birth Cohort 1921 of the Scottish Mental Survey 1932. 
Table 2

Correlations Among Mental Tests for the Aberdeen Birth Cohorts of 1921 ( $N=74$; Above the Diagonal) and 1936 (N = 353; Below the Diagonal)

\begin{tabular}{|c|c|c|c|c|c|c|c|c|c|c|}
\hline \multirow[b]{2}{*}{ Variable } & \multirow[b]{2}{*}{ MHT age 11} & \multirow[b]{2}{*}{ Raven's Matrices } & \multirow[b]{2}{*}{ Block design } & \multirow[b]{2}{*}{ Digit symbol } & \multirow[b]{2}{*}{ Uses of objects } & \multirow[b]{2}{*}{ AVLT } & \multicolumn{2}{|c|}{ ABC1921 } & \multicolumn{2}{|c|}{ ABC1936 } \\
\hline & & & & & & & $M$ & $S D$ & $M$ & $S D$ \\
\hline MHT age 11 & - & $.48 * *$ & $.36 * *$ & $.39 * *$ & .16 & $.29 *$ & 43.1 & 12.7 & 43.0 & 12.7 \\
\hline Raven & $.57 * *$ & - & $.73^{\mathrm{a} * *}$ & $.69^{a * *}$ & $.53^{\mathrm{a} * *}$ & $.45^{\mathrm{a} * *}$ & 29.3 & 9.0 & 35.9 & 8.1 \\
\hline Block Design & $.43 * *$ & $.58 * *$ & - & $.55 * *$ & $.44 * *$ & $.29 *$ & 19.7 & 7.7 & 24.5 & 8.1 \\
\hline Digit Symbol & $.48 * *$ & $.45 * *$ & $.41 * *$ & - & $.48^{\mathrm{a} * *}$ & $.37 * *$ & 30.6 & 10.8 & 43.9 & 11.3 \\
\hline Uses of Objects & $.26^{* *}$ & $.30 * *$ & $.36^{* *}$ & $.26 * *$ & - & $.54^{\mathrm{a} * *}$ & 14.8 & 5.4 & 13.6 & 5.4 \\
\hline AVLT & $.36^{* *}$ & $.24 * *$ & .10 & $.37 * *$ & $.20 * *$ & - & 48.6 & 13.7 & 58.5 & 12.7 \\
\hline
\end{tabular}

Note. $\quad \mathrm{ABC}=$ Aberdeen birth cohort; MHT $=$ Moray House Test; Raven $=$ Raven's Standard Progressive Matrices; AVLT $=$ Auditory Verbal Learning Test. ${ }^{\text {a }}$ Correlation significantly higher in the ABC1921 sample.

$* p<.05$. ** $p<.01$.

1996). Larger correlation coefficients and a larger $g$ factor indicate dedifferentiation; that is, the tests share more variance and less specificity, implying a less differentiated cognitive structure.

The correlations among the five mental tests taken at follow-up were universally higher for the older cohort (see Table 2). Six of the 10 correlations were significantly $(p<.05)$ higher in the older sample. In the ABC1921 and ABC1936 cohorts, the five mental tests at follow-up-approximately age 65 and age 78, respectively-were subjected to principal components analysis. By both the scree slope criterion and the eigenvalues-greater-than- 1 criterion, there was a single component underlying each set of correlations. The first unrotated principal component accounted for $60.6 \%$ of the variance in the older sample and $47.3 \%$ in the younger participants. The scores on the first unrotated component of the five follow-up mental tests were saved for the older and younger samples. The correlation between Moray House Test age-11 scores and the scores on this component were .43 for the ABC1921 sample and .62 for the ABC1936 sample. These correlations were significantly different $(p<.04)$.

The limitations to this analysis are the relatively modest number of participants and the unequal numbers of men and women in the older cohort. However, no study of the dedifferentiation hypothesis has found differences between the sexes, and this aspect of the sample should not affect the correlational structure (Deary et al., 1996; Detterman \& Daniel, 1989; Jensen, 1998; Legree, Pifer, \& Grafton, 1996). The present study cannot decide whether it is the age per se of the two groups or the fact that the older group has lower mean test scores that accounts for the difference in the pervasiveness of the general factor. The ability-level-based and age-based versions of the dedifferentiation hypothesis are difficult to separate without very large samples (Deary et al., 1996).

The data suggest that in samples of participants whom we know are almost identical with respect to their Moray House Test scores at age 11, the older cohort performs less well, the relation between cognitive ability at age 11 and present ability is weaker in the older cohort, and the general factor accounts for more of the variance in the older cohort. The dedifferentiation hypothesis of cognitive aging has proved difficult to test since it was first clearly hypothesized by Lienert (e.g., Lienert \& Crott, 1964; see Deary et al., 1996, for a review). The present analyses offer evidence of its support, especially in view of the close matching of the two groups on mean and variance in childhood psychometric intelligence.

\section{SMS1932 and SMS1947: Contributions to Cognitive Change Across the Life Span}

Gender: LBC1921, ABC1921, and ABC1936. The determinants of cognitive change are a major research focus (Anstey \& Christensen, 2000; Fillit et al., 2002; National Research Council, 2000), and among the possible factors is sex (Meinz \& Salthouse, 1998). The Lothian birth cohort and Aberdeen birth cohort samples provide a rare opportunity to examine the effect of sex on lifelong cognitive change. These data are presented for the first time.

To examine the effects of time and sex on mean changes in mental test scores, the LBC1921 participants with full data are included (i.e., a listwise analysis was conducted), and therefore, there are minor differences in some means compared with Table 1 that are noted in the text. At age 11 , boys $(n=203)$ had a mean Moray House Test score of $46.2(S D=12.7)$ versus the girls' $(n=$ $283)$ mean score of $46.9(S D=11.6)$, a 0.7 -point disadvantage. At approximately age 80 , men $(n=203)$ had a mean Moray House Test score of $59.9(S D=10.7)$ versus the women's $(n=283)$ mean score of 58.1 ( $S D=11.1)$, a 1.8-point advantage. A mixedmeasures analysis of variance of Moray House Test scores was carried out with time as a repeated measure (age 11 score vs. age 80 score) and sex as a between-subjects factor. People had higher scores at age about $80, F(1,484)=817.7, p<.001$. There was a significant Sex $\times$ Time interaction, with men improving more than women over time, $F(1,484)=8.1, p=.005$. The effect of sex on cognitive change from age 11 to about age 80 was explored further using analysis of covariance with age 80 Moray House Test score as the dependent variable, age 11 Moray House Test score as the covariate, and sex as a between-subjects factor. The Moray House Test age 11 score effect was significant, $F(1,483)=374.3, p<$ .001 , partial $\eta^{2}=.44$. The effect of sex also was significant, $F(1$, $483)=8.6, p=.004$, partial $\eta^{2}=.017$.

Therefore, sex accounts for about $1.7 \%$ of the variance in Moray House Test scores in old age after age-11 Moray House Test scores are taken into account. This effect of sex confirms a result that was merely a trend in our earlier report (Deary et al., 2000). It also confirms findings from some other cohorts in which women are more likely to suffer cognitive decline (e.g. Ho, Woo, Sham, Chan, $\&$ Yu, 2001). Meinz and Salthouse (1998) reviewed many studies conducted by Salthouse and his associates and found some evidence for less age-related decline in reasoning ability in men 
versus women. We refer to relative levels of cognitive change rather than decline in our samples because mean Moray House Test scores were higher at follow-up than at age 11 .

The next new analysis attempted to replicate the differential effect of sex on cognitive change across the life span using a different cognitive test in the LBC1921. In the LBC1921, there were 487 people with age-11 Moray House Test scores and scores on Raven's Progressive Matrices at about age 80 years. Descriptive data are shown in Table 3. Men had a nonsignificant disadvantage in Moray House Test scores at age $11, t(1,485)=0.7, p=$ .48 , and a significant advantage in Raven scores at about age 80, $t(1,485)=2.8, p=.005$. The correlation between Moray House Test scores at age 11 and Raven's Matrices scores at about age 80 was .48 and .44 for women and men, respectively. The effect of sex on cognitive change from age 11 to age about 80 was explored using analysis of covariance with age- 80 Raven score as the dependent variable, age-11 Moray House Test score as the covariate, and sex as a between-subjects factor. The Moray House Test age-11 score effect was significant, $F(1,484)=131.2, p<.001$, partial $\eta^{2}=.21$. The effect of sex also was significant, $F(1$, $484)=12.5, p<.001$, partial $\eta^{2}=.025$.

Therefore, sex accounted for about $2.5 \%$ of the variance in Raven test scores in later life after age-11 Moray House Test scores were taken into account. With regard to nonverbal reasoning, aging was kinder to men (cf. Meinz \& Salthouse, 1998). This effect of sex confirmed the effect found for the Moray House Test scores in the LBC1921 at about age 80.

In the next analysis, we used data from the ABC1936 to inquire whether the sex difference in the aging of general mental ability had already occurred at age 65,15 years before the effect on the LBC1921. There were 427 people with age-11 Moray House Test scores and scores on Raven's Progressive Matrices at age 65. Descriptive data are shown in Table 4. Men had a nonsignificant disadvantage in Moray House Test scores at age $11, t(1,425)=$ $1.7, p=.08$, and a nonsignificant advantage in Raven at age 65 , $t(1,425)=1.2, p=.25$. The correlation between Moray House Test age-11 scores and Raven's Matrices age-65 scores was .59 for women and men. The effect of sex on cognitive change from age

Table 3

Descriptive Statistics of, and Correlations Among, Mental Tests for Participants in the Lothian Birth Cohort 1921

\begin{tabular}{lrrrr}
\hline Variable & $M$ & $S D$ & $n$ & MHT age 11 \\
& \multicolumn{5}{c}{ All participants } \\
MHT age 11 & 46.6 & 12.0 & 487 & \\
Raven & 30.9 & 8.7 & 487 & .45 \\
\hline \multicolumn{5}{c}{ Men } \\
MHT age 11 & 46.1 & 12.7 & 204 & \\
Raven & 32.2 & 8.4 & 204 & .44 \\
& \multicolumn{5}{c}{ Women } & \\
MHT age 11 & 46.9 & 11.5 & 283 & .48 \\
Raven & 29.9 & 8.6 & 283 & \\
\hline
\end{tabular}

Note. $\quad$ MHT $=$ Moray House Test $;$ Raven $=$ Raven's Standard Progressive Matrices. For all correlations, $p<.001$.
Table 4

Descriptive Statistics of, and Correlations Among, Mental Tests for Participants in the Aberdeen Birth Cohort 1936

\begin{tabular}{lrrrc}
\hline Variable & $M$ & $S D$ & $n$ & MHT age 11 \\
& \multicolumn{5}{c}{ All participants } \\
MHT age 11 & 42.3 & 13.0 & 427 & \\
Raven & 35.3 & 8.7 & 427 & .58 \\
\hline \multicolumn{5}{c}{ Men } \\
MHT age 11 & 41.2 & 13.7 & 210 & \\
Raven & 35.8 & 8.4 & 210 & .59 \\
\hline & \multicolumn{5}{c}{ Women } \\
MHT age 11 & 43.4 & 12.2 & 217 & .59 \\
Raven & 34.9 & 8.9 & 217 \\
\hline
\end{tabular}

Note. $\quad$ MHT $=$ Moray House Test Raven $=$ Raven's Standard Progressive Matrices. For all correlations, $p<.001$.

11 to age 65 was explored using analysis of covariance with age-65 Raven score as the dependent variable, age-11 Moray House Test score as a covariate, and sex as a between-subjects factor. The Moray House Test age-11 score effect was significant, $F(1,424)=226.4, p<.001$, partial $\eta^{2}=.35$. The effect of sex also was significant, $F(1,424)=7.3, p=.007$, partial $\eta^{2}=.017$. Therefore, sex accounted for about $1.7 \%$ of the variance in Raven test scores in old age after age-11 Moray House Test scores were taken into account.

With regard to verbal and nonverbal reasoning, therefore, aging was kinder to men in the Scottish 1921- and 1936-born cohorts This effect of sex on Raven scores by age 65 confirmed the effect found in the Lothian birth cohort at about age 80. Therefore, the causes of this sex difference may be sought prior to age 65 years. New to these analyses is the significant effect of sex on cognitive change, with surviving men performing relatively well at about age 80 despite there being no sex difference at age 11 . Sex appears to account for just under $2 \%$ of the variance in cognitive test scores at about age 80 , and this contribution is independent of the contribution from childhood ability test scores.

Some of the effect of sex on cognition found here may be sought in the causes of the differential survival of men and women. Men have a shorter average life span. They are affected at younger ages by, for example, cardiovascular disease, which is associated with lower cognitive function (Breteler, Claus, Grobbee, \& Hoffman, 1994; Fillit et al., 2002; Haan, Shemanski, Jagust, Manolio, \& Kuller, 1999). Because cardiovascular disease causes death and disability, people suffering from cardiovascular diseases are less likely to be represented in our follow-up studies. Therefore, men tested in the present cohorts might represent a relatively cognitive spared survivor group.

Blood micronutrients: $A B C 1921$ and ABC1936. Our studies on the origins of variation in age-related cognitive performance indicate that up to about $50 \%$ of variation is determined by mental ability in childhood (Deary et al., 2000). The sources of the remaining $50 \%$ or so are uncertain. We have addressed the possible contribution of the nutritional environment to age-related variations in cognitive function. We recruited 199 of the ABC1921 
participants and 148 of the ABC1936 participants to a longitudinal research program on nutrition, brain aging, and health. Fasted blood samples were collected at home and analyzed for vitamin $\mathrm{B}_{12}$, folate, and homocysteine. Folate was estimated both as plasma folate and as folate/mg red blood cell protein (Duthie et al., 2002). Fasted samples were also analyzed for antioxidant substances-vitamin $\mathrm{C}$, vitamin $\mathrm{E}$, and carotenoids ( $\alpha$ - and $\beta$-carotene, lutein/zeaxanthin, lycopene, $\beta$-cryptoxanthin)—which will be the subject of future reports.

Adjustment for childhood mental ability in these analyses is particularly informative; it affords the estimation of the potential contribution of micronutrient concentrations to lifelong change in cognitive function. Positive relationships were observed in the older cohort between plasma folate, vitamin $\mathrm{B}_{12}$, and Mini-Mental State Examination scores ( $r \mathrm{~s}=.20$ and .19 , respectively; Duthie et al., 2002). After adjustment for childhood mental ability, there was a significant inverse correlation between plasma homocysteine and scores on Raven's Matrices $(r=-.22)$.

The B vitamins and homocysteine affect brain function. Homocysteine shows reliable individual differences (McKinley, Strain, McPartlin, Scott, \& McNulty, 2001). In our studies, because we were able to control for childhood IQ, we could conclude that both vitamin $\mathrm{B}_{12}$ and folate are significant contributors to the agerelated variation in cognitive performance (Duthie et al., 2002). A mechanistic account of these contributions may be essayed. Vitamin $B_{12}$ deficiencies may perturb normal brain function by decreasing $\mathrm{S}$-adenosyl methionine concentrations. Deficiencies of vitamin $\mathrm{B}_{12}$ increase plasma homocysteine concentrations, which in turn can be oxidized to form metabolites and reactive oxygen species that are known to be toxic to the vascular endothelium.

In summary, the availability of childhood mental ability data allowed a direct implication to be drawn: Decreased vitamin $B_{12}$ and folate and increased homocysteine concentrations contribute negatively to age-related cognitive change. These results and our planned studies of antioxidants will inform the debate on the benefits of antioxidant supplementation or the inclusion of more antioxidant-rich foods in the diets of older people (Fillit et al., 2002).

\section{SMS1932 and SMS1947: Contributions to Mortality and Morbidity in Later Life}

The relationship between cognition and disease is considered largely asymmetrically in terms of causal direction. The focus is mostly on the effects of specific pathologies on mental ability. Less often are the consequences of mental ability differences for future physical health investigated (Korten et al., 1999). It is those hypotheses related to this second causal direction that are relevant to the SMS1932 and SMS1947 cohorts, where there is a lag of nearly 70 and 55 years, respectively, between the original cognitive data and any current measures of health. The definition of health in old age is itself problematic, deserving discussion (MacIntyre, 1986), but mortality is an unequivocal indicator. Moreover, mental ability in old age is a recognized predictor of death (Korten et al., 1999; Neale, Brayne, \& Johnson, 2001) and, as previously discussed, is strongly influenced by childhood intelligence (Deary et al., 2000). The Scottish Mental Surveys provided the first opportunity in the scientific literature to examine the hypothesis that childhood psychometric intelligence is a signifi- cant influence on longevity. It was known that childhood social class and education - both strongly correlated with psychometric intelligence-were associated with longevity (Davey Smith, Hart, Blane, \& Hole, 1998; Davey Smith, Hart, Hole, et al., 1998; Kunst \& Mackenbach, 1994), but no previous study linked childhood ability to survival to old age. The exception to this is the link between linguistic ability and longevity in the nun study (Snowdon, Greiner, Kemper, Nanayakkara, \& Mortimer, 1999; Snowdon, Ostwald, \& Kane, 1989). Neale et al. (2001) stated that

it seems that cognitive function itself is a marker of the human organism's capacity to survive. To some extent cognitive function itself is a marker of cumulative exposure and this may explain the findings. Only very long-term cohorts from earlier ages can clarify how independent the effect is. (p. 1388)

The SMS1932 provided clarification, although ability at age 11 still reflects exposure to an extent.

Childhood psychometric intelligence and all-cause and cancerbased mortality: The SMS1932 cohort. We originally tested whether Moray House Test 1932 scores predicted mortality in cohort members who attended Aberdeen city schools $(n=2,792)$ up until December 31, 1996 (Whalley \& Deary, 2001). We were aided by the centralization and computerization of death certificates at Register House, Edinburgh, Scotland; the Scottish Community Health Indices; and the United Kingdom's National Health Service Central Register in Southport, England. We were thus able to trace $2,230(79.9 \%)$ of the target sample, of whom 1,084 (646 men, 438 women) had died. Higher childhood psychometric intelligence was associated with significantly improved survival to age $76(p<.0001)$. One-standard-deviation-lower IQ-type score-15 IQ points difference-was associated with a relative survival of $79 \%$ (95\% confidence interval $=75 \%-84 \%$ ). A difference of 30 IQ points $(2 S D \mathrm{~s})$ resulted in a relative survival of $63 \%(95 \%$ confidence interval $=56 \%-71 \%$ ). Notably the association was weaker for men than for women. A 30-IQ-point difference was associated with a relative survival of only $51 \%$ (95\% confidence interval $=42 \%-61 \%)$ in women but $68 \%(95 \%$ confidence interval $=58 \%-80 \%)$ in men. This observation appeared to relate to a paradoxical high mortality rate in men from the highest childhood IQ-type score quartile serving in the armed forces during World War II, 1939-1945. The association between childhood psychometric intelligence and mortality is illustrated for men and women, respectively, in Figure 4. Note the increased deaths during World War II (1940 to 1945 in the bottom half of Figure 4), especially among the higher two IQ quartiles.

Our subsequent research has explored this association between childhood psychometric intelligence and mortality by collecting information about specific causes of mortality. In our first analyses, we found that, overall, people with lower childhood psychometric intelligence were more likely to die from lung and stomach cancers (Deary, Whalley, \& Starr, 2003; and see Figure 5). Interestingly, these are the same cancers that are associated with indices of childhood social privation and factors that are linked to health behaviors, such as smoking (Davey Smith, Hart, Blane, \& Hole, 1998; Davey Smith, Hart, Hole, et al., 1998).

In addition to empirical contributions, we have proposed four possible mechanisms by which the association of childhood psychometric intelligence and survival might act (see Figure 6): 

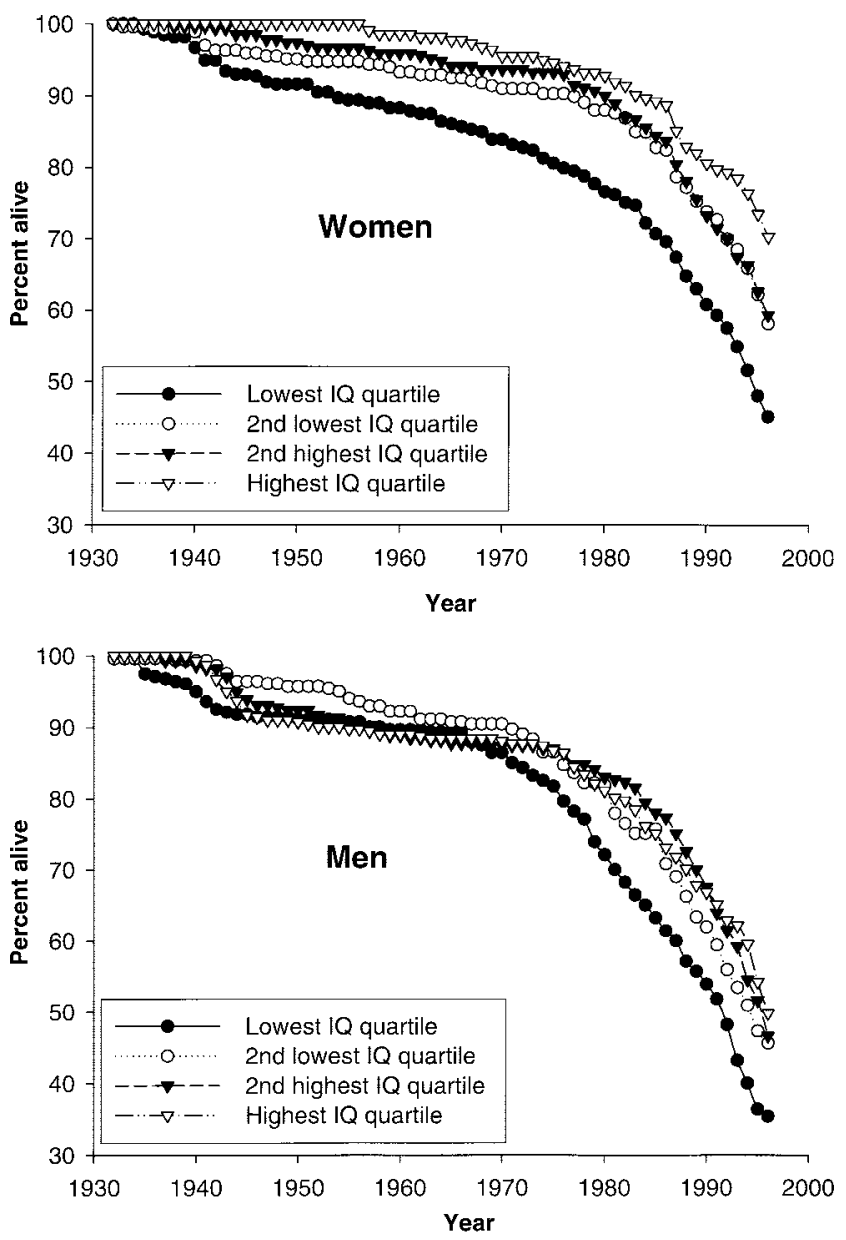

Figure 4. Relationship between IQ at age 11 in the Scottish Mental Survey 1932 and survival to age 76 on January 1, 1997, for women and for men. From "IQ at Age 11 and Longevity: Results From a Follow Up of the Scottish Mental Survey 1932" (Figure 1, p. 157), in Brain and Longevity: Perspectives in Longevity, by C. Finch, J.-M. Robine, \& Y. Christen (Eds.), 2003, Berlin: Springer. Copyright 2003 by Springer. Adapted with permission.

1. Childhood psychometric intelligence might be a record of bodily insults that are themselves deleterious to later health. For example, we described an association between low birth weight and lower SMS1932 Moray House Test score for those cohort members born at the Simpson's Memorial Maternity Pavilion in Edinburgh in 1921 (Shenkin et al., 2001). This was consistent with data from more contemporaneous birth cohorts (Lagerstrom, Bremme, Eneroth, \& Janson, 1994; Sorensen et al., 1997). Low birth weight is also associated with insulin resistance and autonomic dysfunction in adulthood (Phillips \& Barker, 1997) and therefore, theoretically, with late-life cardiovascular disease. However, twin data cast doubt on the importance of intrauterine growth retardation and later life morbidity (Christensen, Vaupel, Holm, \& Yashin, 1995; Vagero \& Leon, 1994), in particular that due to cardiovascular disease.

2. Childhood psychometric intelligence might be an index of bodily system integrity that does not posit specific bodily insults but assumes a strong correlation between neurodevelopment and that occurring in other organs. An extreme example of this would be in Down's syndrome in which IQ is a strong predictor of survival despite major, externally guided control of other potential pathways (e.g., lifestyle choices or unsafe environments).

3. Childhood psychometric intelligence might predict healthy behaviors. This would be similar to the pathway hypothesized for the association between conscientiousness and survival found in the long-term follow-up of the Terman study (Schwartz et al., 1995).

4. Childhood psychometric intelligence might predict entry into safer environments, especially in the workplace. We would hypothesize that the impaired survival of high mental ability men during World War II is a counterexample of this effect.

Structural equation modeling indicated that childhood psychometric intelligence mediated the effects on mortality of other significant childhood factors available to us, namely, parental occupation and overcrowding (Whalley \& Deary, 2001). After a path was entered between IQ at age 11 and age at death (parameter weight $=.18, p<.05)$, there was no significant direct effect of either father's occupation or overcrowding (based on the average of houses in the school catchment area) on age at death.

We were unable to estimate the contribution of each of our four proposed causal pathways on survival. It is possible that the impact of childhood intelligence on mortality proceeds by subtle, dynamic processes-described by Dickens and Flynn (2001) — whereby environmental effects can become greatly multiplied from small initial inequalities.

Childhood psychometric intelligence and all-cause and cancerbased mortality: The SMS1947 cohort. The next analyses are new and represent our first examination of whether the association between childhood psychometric intelligence and mortality is apparent in the SMS1947. The records of the representative 6-day sample of the SMS1947 were located in the Scottish Council for Research in Education. Nine hundred and eight people had the following SMS1947 information: surname, forename, date of birth, and psychometric intelligence score at age 11. The Scottish Record Linkage System (SRLS; Heasman \& Clarke, 1979) was used to link SMS1947 cognitive test scores to the following health records in Scotland: Registrar General's death records between 1968 and 2000, Scottish Morbidity Records 1 (SMR 1) records from 1968 to 2000 (all hospital discharge diagnoses), SMR 4 records from 1968 to 2000 (mental illness discharges), and Scottish Cancer Registry records (SMR6/SOCRATES) from 1968 to 1998. Within SMR1 instances of cardiovascular disease were recorded (based on ICD8, ICD9, and ICD10 diagnostic codes).

SRLS uses probability-matching methods. A subset of records are compared. Those that share a minimum level of identifying information (name, based on Soundex code, and all elements of date of birth) are given a probability weight. This is converted into absolute odds, which supports the linkage decision. A threshold is identified above which pairs are taken as linked and below which the pairs are not accepted as linked. This threshold is determined by actual inspection of pairs of records.

Table 5 contains the results. Of the 908 people with surviving records in the 6-day sample of the SMS1947, 561 were linked to at least one hospital discharge, 125 were dead, 98 had a cardiovascular disease diagnosis, 78 had a diagnosis of cancer, and 37 had a hospital admission for mental illness. Following the link- 


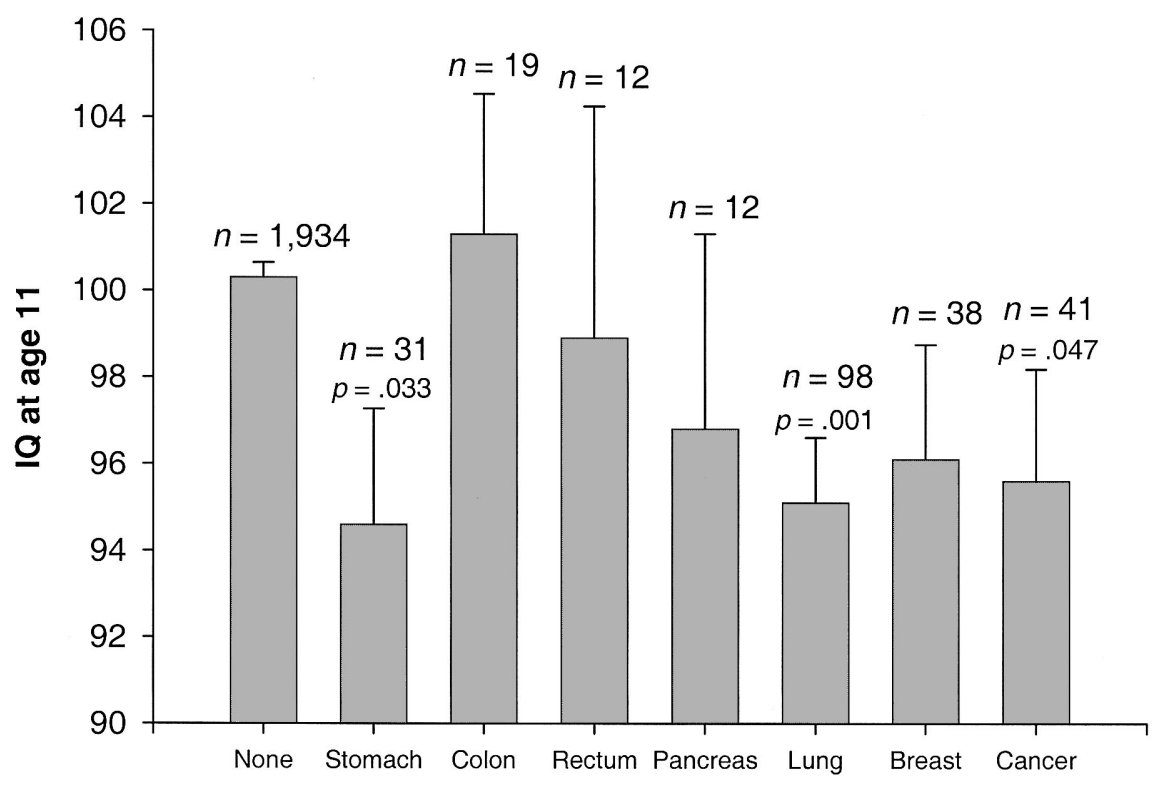

Type of cancer on death certificate

Figure 5. Mean age 11 IQ score for people in the SMS1932 who died with different types of cancer. From Brain and Longevity: Perspectives in Longevity (p. 160, Figure 2), by C. Finch, J.-M. Robine, \& Y. Christen (Eds.), 2003, Berlin: Springer. Copyright 2003 by Springer. Adapted with permission.

ages, people with and without the relevant outcomes were compared by analysis of variance. Including both men and women, mental ability test score at age 11 years was significantly associated with death $(p<.001)$, all-cause hospital discharge $(p<$ $.001)$, and heart disease $(p<.05)$. There was a significant effect of psychometric intelligence at age 11 on cancer outcomes in women $(p<.05)$. There was no significant effect of psychometric intelligence on mental illnesses. To obtain hazard ratios and their 95\% confidence intervals (Table 5), Cox proportional hazard regression was used, with age-11 mental test score as a predictor (with and without sex included as a predictor) and mortality and other disease outcomes as the dependent variables.

These analyses on the SMS1947 show that the association between childhood psychometric intelligence and mortality exists in this Scotland-wide, representative sample. The effect is not, therefore, confined to the special temporal and geographical circumstances that existed in Aberdeen for the 1921-born cohort. With evidence that the ability-longevity association exists in other cultures-even where the environmental circumstances are controlled (Snowdon, Greiner, et al., 1999; Snowdon, Ostwald, \&

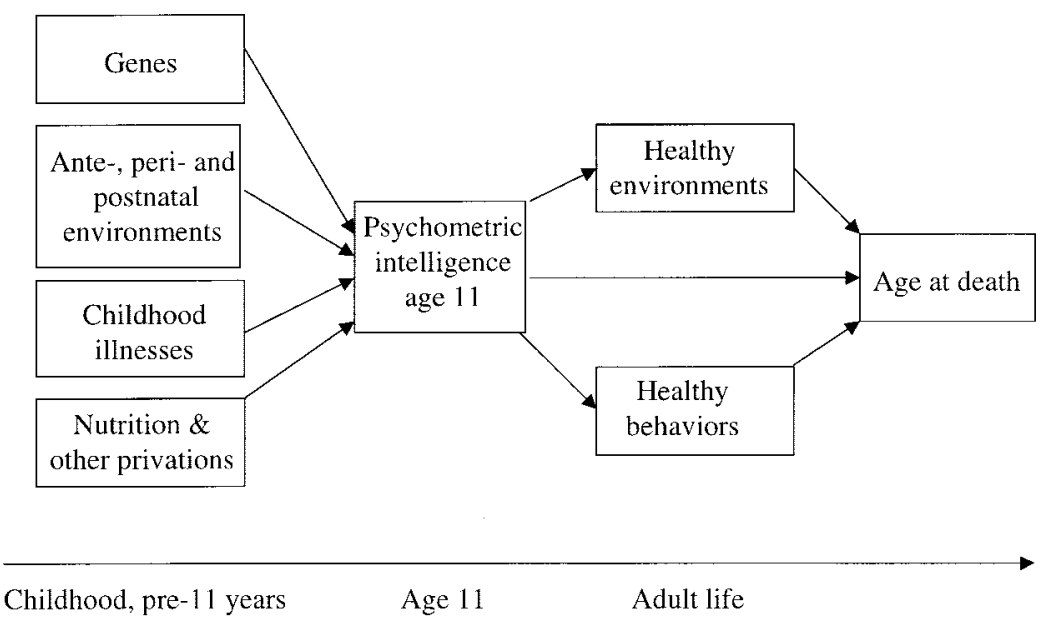

Figure 6. Some possible influences and pathways linking mental ability in childhood and survival. From Brain and Longevity: Perspectives in Longevity (p. 162, Figure 3), by C. Finch, J.-M. Robine, \& Y. Christen (Eds.), 2003, Berlin: Springer. Copyright 2003 by Springer. Adapted with permission. 
Table 5

Results of Linking 6-Day Sample of Scottish Mental Survey of 1947 to Mortality and Morbidity Records

\begin{tabular}{|c|c|c|c|c|c|c|c|c|c|}
\hline \multirow[b]{2}{*}{ Outcome } & \multirow{2}{*}{$\begin{array}{l}n \text { with } \\
\text { outcome }\end{array}$} & \multirow{2}{*}{$\begin{array}{l}n \text { without } \\
\text { outcome }\end{array}$} & \multicolumn{2}{|c|}{$\begin{array}{c}\text { IQ of people } \\
\text { with } \\
\text { outcome }\end{array}$} & \multicolumn{2}{|c|}{$\begin{array}{l}\text { IQ of people } \\
\text { without } \\
\text { outcome }\end{array}$} & \multirow[b]{2}{*}{$p$} & \multirow{2}{*}{$\begin{array}{l}\text { Hazard ratio of IQ } \\
\qquad(95 \% \mathrm{CI})\end{array}$} & \multirow{2}{*}{$\begin{array}{c}\text { Adjusted (for sex) } \\
\text { hazard ratio } \\
(95 \% \mathrm{CI})\end{array}$} \\
\hline & & & $M$ & $S D$ & $M$ & $S D$ & & & \\
\hline \multicolumn{10}{|l|}{ Death } \\
\hline All participants & 125 & 783 & 97.7 & 13.9 & 104.6 & 17.0 & $<.001$ & $.977(0.966-0.988)$ & $.975(0.964-0.986)$ \\
\hline Men & 81 & 356 & 98.4 & 14.3 & 106.6 & 17.2 & $<.001$ & & \\
\hline Women & 44 & 427 & 96.4 & 13.1 & 103.0 & 16.8 & $<.05$ & & \\
\hline \multicolumn{10}{|l|}{ Cancer } \\
\hline All participants & 78 & 830 & 101.3 & 16.0 & 103.9 & 16.9 & .23 & $.993(0.979-1.006)$ & $.993(0.979-1.007)$ \\
\hline Men & 35 & 402 & 105.7 & 15.5 & 105.0 & 17.1 & .80 & & \\
\hline Women & 43 & 428 & 97.7 & 15.6 & 102.8 & 16.6 & .05 & & \\
\hline \multicolumn{10}{|c|}{ Cardiovascular disease } \\
\hline All participants & 98 & 810 & 100.1 & 15.1 & 104.1 & 17.0 & $<.05$ & $.987(0.975-1.000)$ & $.986(0.973-0.998)$ \\
\hline Men & 59 & 378 & 101.5 & 16.6 & 105.6 & 17.0 & .09 & & \\
\hline Women & 39 & 432 & 97.9 & 12.3 & 102.7 & 16.8 & .08 & & \\
\hline \multicolumn{10}{|l|}{ SMR 1 discharge } \\
\hline All participants & 561 & 347 & 102.0 & 16.2 & 106.3 & 17.4 & .001 & $.990(0.985-0.995)$ & $.990(0.985-0.995)$ \\
\hline Men & 262 & 175 & 102.2 & 15.7 & 109.3 & 17.8 & .001 & & \\
\hline Women & 299 & 172 & 101.8 & 16.3 & 103.3 & 16.5 & .36 & & \\
\hline \multicolumn{10}{|l|}{ SMR 4 discharge } \\
\hline All participants & 37 & 871 & 100.4 & 16.8 & 103.8 & 16.8 & .23 & $.988(0.968-1.008)$ & $.987(0.967-1.007)$ \\
\hline Men & 21 & 416 & 102.3 & 16.4 & 105.2 & 17.0 & .45 & & \\
\hline Women & 16 & 455 & 97.9 & 17.5 & 102.5 & 16.5 & .28 & & \\
\hline
\end{tabular}

Note. All outcomes refer to the period between 1968 and 2000, except cancer, which refers to the period 1968-1998. SMR = Scottish Morbidity Records.

Kane, 1989)—future research must examine the specificity of the effect and seek the causal pathways involved. The present analyses provide additional information by identifying some specific illnesses—-such as heart disease (Hart et al., 2003) — that might mediate the childhood intelligence-mortality association.

Childhood psychometric intelligence and disease syndromes in the ABC1921. Multiple pathology is common in old age. To investigate the effects of disease on cognition, we previously selected a sample of people age 70 years and over, who had no reported disease and were on no regular medication (Deary, Starr, \& MacLennan, 1998; Starr, Whalley, Inch, \& Shering, 1992). This group comprised only $10 \%$ to $15 \%$ of the total population over 70 years old in the locale. Hence a definition of health that depends on the absence of disease may not be useful in samples of a similar age to the ABC1921 cohort. At initial follow-up of the ABC1921 in 1998 (Starr et al., 2000), 57 (24.3\%) of the 234 participants (111 men, 123 women) had no recorded disease and were on no regular medications. There was no significant difference in Moray House Test age-11 scores between those with $(M=39.7,95 \%$ confidence interval $=37.5-41.9)$ and those without $(M=40.1,95 \%$ confidence interval $=37.0-43.2)$ current disease, $F=0.04, p=.84$. Except for dementia (see Whalley et al., 2000; and see below), there was no significant difference between Moray House Test scores for any specific diagnostic category. This may reflect an attenuation of the effect of childhood psychometric intelligence on disease with attrition of those cohort members with lower scores. It may also be due to exclusion of cohort members with more severe disease from reattendance for data collection. Any deleterious influence of childhood psychometric intelligence on survival persisting into the 9 th decade of life may be largely accounted for by the exponential increase in dementia, and thus dementia-related deaths, in old age.

Childhood psychometric intelligence and early-and late-onset dementia in the SMS1932. The SMS1932 records are relevant to dementia research. The SMS1932 survivors have experienced over half the risk period for dementia. We used the SMS1932 data to compare childhood intelligence scores for (a) all 1921-born men and women who were detected as early-onset dementia cases in the Scottish National Early Onset Dementia survey (dementia onset before age 64; Whalley, Thomas, McGonigal, et al., 1995; Whalley, Thomas, \& Starr, 1995) with 1921-born controls and (b) 1921-born, late-onset dementia cases with 1921-born controls (in Aberdeen, Scotland; Whalley et al., 2000). SMS1932 test scores did not distinguish between the 59 children who later developed early-onset dementia and 118 matched control participants. However, when the 59 early-onset dementia participants were compared, not with local matches but with the entire SMS1932 scores $(N=87,498)$, the cases scored significantly below the national mean score. We interpreted these observations quite conservatively and concluded that lower childhood intelligence was not a risk factor for early-onset dementia, but we might have overcontrolled for local factors and failed to give proper emphasis to the differences between the cases and the national mean values from the SMS1932.

In the same report (Whalley et al., 2000), we compared childhood intelligence scores from the SMS1932 between 79 1921-born Aberdeen residents who developed late-onset dementia (after age 64) and 1921-born Aberdeen residents who had not developed dementia by the time they were 77 years old. Of Aberdeen residents born in 1921 and alive in 1985, childhood intelligence was 
significantly lower in those who developed late-onset dementia between 1985 and 1998 than in those who did not. Intelligence differences were attributable to dementia cases with onset after age 72.

This was the most comprehensive study of its type, considerably extending the report by Snowdon et al. (1996; and see LaRue \& Jarvik, 1986) that linguistic ability in young adulthood was related to late-onset dementia and the reports by others that people with fewer years of education and lower educational attainments are at greater risk of dementia (Fratiglioni, Grut, \& Forsell, 1991; Katzman, 1993; Stern et al., 1994). Our study was notable not only for the inclusion of valid and reliable measures of childhood mental ability but also for the completeness of matching between childhood intelligence archives and contemporary health records and for the separate study of early- and late-onset dementia. The results concerning late-onset dementia and age-11 psychometric intelligence were discussed in terms of the cerebral reserve hypothesis of cognitive aging (Jenkins, Fox, Rossor, Harvey, \& Rossor, 2000; Mori, Hirono, \& Yamashita, 1997; Reynolds, Johnston, Dodge, DeKotsky, \& Ganguli, 1999; Satz, 1993; Schofield, Logroscino, Andrews, Albert, \& Stern, 1997), although a more sophisticated understanding of the relation may be achievable using Arendt's (2001) notion that Alzheimer's disease is associated with problems of brain self-organization.

Childhood psychometric intelligence and frailty in the ABC1921. Many so-called diseases that are common in old age are defined in terms of a threshold on a continuous physiological measure. Examples include hypertension, which is diagnosed above specified systolic and diastolic blood pressures; diabetes mellitus, which is diagnosed above specified blood glucose levels; and chronic obstructive pulmonary disease, which is diagnosed below specified respiratory function measures. Usually there is no sudden increase in mortality risk once these thresholds are crossed: Rather, risk relates directly to the value of the physiological variable. In the case of hypertension and diabetes, the agreed diagnostic thresholds have changed over recent years, increasing the numbers of people labeled as having the disease. Measuring certain key physiological variables may often be more informative about health in old age than undertaking a diagnostic process.

The situation with physical diseases parallels that of the relationship between cognitive impairment and dementia, for which merely making the diagnosis is not particularly helpful (Foy \& Starr, 2000). The relationship between cognition and dementia provides an example of a further strength of the quantitative as opposed to categorical approach to health. It has long been hypothesized that those with higher premorbid mental ability have greater cerebral reserve to resist dementia (Kay, Beamish, \& Roth, 1964; see Satz, 1993, for a fuller and more recent account, and Gold, Deary, MacLeod, \& Frier, 1995, for a critique of the concept). The same physiological reserve concept is invoked to define frailty in old age and the related idea of biological aging (Anstey \& Smith, 1999).

At the first wave of follow-up of the ABC1921, bivariate correlations between Moray House Test score from the SMS1932 and the physiological variables or factors found only walking time $\left(r_{s}\right.$ $=-.15, p=.05$ ) to reach significance (Starr et al., 2000). Since many physiological measures are interrelated, we undertook multivariate modeling. The optimum model for the basket of variables associated with greater physiological reserve comprised significant contributions from greater demispan, male gender, deprivation category, and the interaction between gender and lower deprivation category.

The inclusion of demispan as an independent variable also has its psychometric parallel. Unlike height, which decreases in old age, demispan remains fairly constant (Bassey, 1998; Morgan, 1998). Vertebral deformities associated with osteoporosis correlate with loss of height and can be estimated from the difference between arm span and current height in older people after adjusting for age and arm span itself (Verhaar, Koele, Neijzen, Dessens, \& Duursma, 1998). Psychometric, just as anthropometric, measures also comprise those that are more-or-less subjected to change with aging. Thus, the NART (Nelson, 1982) is used to measure premorbid or prior intelligence to infer the amount of change in current mental ability measured in old age (Crawford et al., 2001; Starr et al., 1992).

The next analyses - between height in old age, childhood intelligence from the SMS1932, and genetic factors-are novel. The absence of early-life physiological data is, as indicated above, a serious problem when seeking to determine the influence of childhood psychometric intelligence on late-life physiological function in the ABC1921. Apart from demispan, there are few crystallized physiological measures that inform about original physiological reserve. This loss is emphasized when we examine height at initial follow-up, adjusting for demispan.

The Pearson correlation coefficient between demispan and height at initial follow-up of the ABC1921 is .77, remarkably similar to that between age-11 and age-77 Moray House Test scores (Deary et al., 2000). There was a significant univariate association between childhood psychometric intelligence and height at about age $77, F(1,171)=4.06, p=.045$, but this became nonsignificant once demispan was adjusted for. However, demispan itself, inasmuch as it correlates with young adult height, is likely to be associated with childhood psychometric intelligence because the positive correlation between psychometric intelligence and height is well established in children (Weinberg, Dietz, Penick, \& McAlister, 1974) and young adults (Teasdale, Owen, \& Sorensen, 1991). In our sample, the relationship persists into old age with the Pearson correlation coefficient between the Raven's Progressive Matrices and height in the ABC1921 being .25 ( $p=$ .001). Raven's score remained significantly associated with height $(p=.038)$ even after we adjusted for demispan.

Women suffer more from osteoporosis than do men in old age, and gender was a highly significant predictor of height in the $\mathrm{ABC} 1921, F(2,178)=32.9, p<.001$, with men $5.8 \mathrm{~cm}$ taller than women $(95 \%$ confidence interval $=3.8-7.8)$ even after adjusting for demispan. With gender entered in the model, Raven's score remained significantly associated with height, $F(5,89)=6.11$, $p=.014$. The epsilon4 allele of the gene for $A P O E$ is associated with increased risk of cognitive decline in old age (MacLullich, Seckl, Starr, \& Deary, 1998; Deary et al., 2002; although Deary, Whalley, et al., 2003, did not find a significant effect for Raven's Matrices). The APOE epsilon4 allele also substantially increases risk of osteoporotic hip fractures (Cauley et al., 1999) and is associated with lower bone mineral mass in postmenopausal women (Shiraki et al., 1997). Adding this to the model predicting height at about age 77 in the ABC1921 increased adjusted $R^{2}$ to .667 , with $A P O E$ epsilon4 participants being significantly shorter 
$(F=5.89, p=.016)$ and Raven's score still remaining a significant contributor to the model $(F=5.28, p=.023)$.

The complex relationship between height and intelligence illustrates the importance of considering confounding. Without relevant genotypes and a proxy for an early-life physiological measure, we could have inferred a more direct association between childhood psychometric intelligence and height in old age. The relevance of genetic variability in $A P O E$ to both intelligence and height illustrates the care required when examining possible causality. Although there may be good a priori reasons to assume that intelligence influences height (e.g. more healthy behaviors), there may be independent factors that affect both intelligence and height. The possibility of such confounding is greater in models where a large proportion of the variance remains unexplained. One great advantage of the SMS1932 follow-up study is that knowing childhood intelligence substantially reduces the proportion of unexplained variance in old-age intelligence and thus allows investigation of the effects of physical health on cognition to be undertaken more securely.

Childhood intelligence and functional independence. Measures of physical fitness correlate strongly with functional independence in older people (Davis, Ross, Preston, Nevitt, \& Wasnich, 1998; Morey, Pieper, \& Cornoni-Huntley, 1998). At initial follow-up of the ABC1921, we measured functional independence with the Barthel index, the recommended scale of both the Royal College of Physicians and the British Geriatrics Society for U.K. residents (Joint Workshop of the Research Unit of the Royal College of Physicians and the British Geriatrics Society, 1992). Barthel scores correlated poorly with physiological measures with the exception of walking time, and this probably reflects the scale's loading toward locomotor ability (Starr et al., 2000).

Childhood mental ability from the SMS1932 at age 11 was a significant predictor of functional independence at age about 77 in our sample with a small-to-moderate effect size $(r=.24, p<$ .001). Once its effects were controlled for, no other socioeconomic variable was of significance. Moreover, childhood psychometric intelligence remained significant $(F=4.59, p=.034)$ even once walking time and current mental ability, as measured by Raven's score, were taken into account. One possible explanation of this association is that people with higher childhood mental abilities are better at developing coping strategies when impairment of physiological function occurs in old age (Gill, Robison, \& Tinetti, 1997). Alternatively, people who are able to deal successfully with the challenge of disease in old age may also rise to the challenge of mental ability tests now and when they were 11 years old. Education is a significant socioeconomic predictor of late-life disability in many different populations (Guralnik et al., 1993; Shetterly, Baxter, Morgenstern, Grigsby, \& Hamman, 1998; Zimmer, Liu, Hermalin, \& Chuang, 1998). Previous studies were unable to examine childhood mental ability. However, it is likely that this would correlate highly with educational attainment in the populations studied. The SMS1932 data suggest that education may be acting as a proxy for childhood psychometric intelligence in other studies. Our data are strong in this regard because the Moray House Test was taken at age 11, when there were no differences among participants with respect to years of education.

Summary of contributions to mortality and morbidity in later life. Premature death, lung and stomach cancers, late-onset dementia, and loss of functional independence are important health outcomes. The significant relationship of childhood psychometric intelligence to these health outcomes-especially where they are independent of childhood sociodemographic variables-in the ABC1921 of the SMS1932 and the 6-day sample of the SMS1947 suggests that early-life mental ability is a significant contributor to late-life health inequalities (Wood \& Bain, 2001). However, caution is needed before inferring any causality in this relationship. The link between childhood psychometric intelligence and either specific pathology (with the exception of dementia) or physical frailty is unproven, and thus the pathway by which childhood psychometric intelligence relates to ill health in old age is unclear. Replication of these results in larger samples with incorporation of early-life physical data into health models is needed to aid investigation of possible mechanistic pathways and thus potential beneficial interventions.

\section{Conclusion}

\section{Scottish Mental Survey-Based Follow-Up Research to Date}

In the years since we became aware of the existence of the SMS1932 and SMS1947 data, these surveys have contributed new information on the stability of psychometric intelligence, the determinants of lifetime cognitive change, and the impact of mental ability differences in youth to health in old age. Examples were given above. Others include our validating the NART as an estimate of premorbid-prior IQ by showing that NART scores at about age 78 correlate .69 with age-11 Moray House Test scores in the ABC1921 (Crawford, Deary, Starr, \& Whalley, 2001) and our showing that brain white matter lesions detected on magnetic resonance imaging are associated with cognitive test scores at about age 78 but not with age-11 Moray House Test scores, suggesting the conclusion that the causes of these brain lesions affect cognitive aging independently of childhood intelligence (Deary, Leaper, et al., 2003; Leaper et al., 2001).

New analyses in this report contributed the longest and largest follow-up study of the stability of psychometric intelligence, evidence of dedifferentiation of mental abilities from age about 65 to age about 77 , evidence concerning sex as a determinant of the aging of reasoning ability, evidence that age-11 psychometric intelligence influences survival and hospital admissions for illnesses up to age 65 , and an understanding of the association between intelligence and height in old age.

\section{Ongoing Research}

The SMS1932 and SMS1947 data are being applied to two main questions. First, they are uniquely suited to inquiring about the determinants of cognitive aging, because they can provide earlylife mental ability data and, combined with cognitive data from later life, allow the calculation of actual cognitive change. Ongoing research projects include our assessing the following contributions to differential cognitive aging: genetic factors, endocrine factors, illness, diet, brain white matter lesions, education, smoking, and intellectual and social engagement. For these purposes, we are recruiting ABC1936 survivors into Phase 2 of follow-up (after 2 years) and ABC1921 survivors into Phase 4 of follow-up (3.75 years after the first follow-up, at intervals of about 1.25 years). 
Because we observe two birth cohorts, we are able to contrast those factors predictive of cognitive improvement or decline in the younger cohort with those in the other, older cohort. Geographical variation between cohorts permits a further level of analysis to be introduced that examines the consistency of observations between Lothian and Aberdeen.

Second, combined with the comprehensive and accessible health and other public records in Scotland and the rest of the United Kingdom, the SMS data can be used to study the contribution of early-life mental ability to inequalities in health and well-being later life. Planned research projects include database linking of the entire SMS1932 records $(N>80,000)$ to mortality and morbidity records in Scotland; database linking of the full psychometric and social data from the 6-day sample of the SMS1947 to health records in Scotland, and database linking of the SMS1932 records to midlife health and social data from a large public health study begun in the 1970s in the west of Scotland (Davey Smith, Hart, Blane, \& Hole, 1998; Davey Smith, Hart, Hole, et al., 1998). Some analyses from the last-mentioned project have now been published, and they show that higher childhood IQ is still related to less all-cause and cardiovascular mortality, after adjusting for social class and deprivation, and to increased smoking cessation by midlife (Hart et al., 2003; Taylor et al., 2003).

Both of these questions-age-related cognitive change and health inequalities in later life-are national as well as international research priorities (Fillit et al., 2002; National Research Council, 2000; Wood \& Bain, 2001).

\section{Future Plans}

The cohort studies based on the SMS data are not yet large or long enough to address some of our principal interests. To detect gene-environment contributions to a continuously distributed trait such as normal cognitive aging, we require thousands rather than hundreds of participants (National Institute of Aging Working Group on Aging and Genetic Epidemiology, 2001). The ABC1936 sample was conceived as a pilot study for a larger, Scotland-wide study in which the aim would be to recruit thousands of survivors of the SMS1947 and to follow them up into old age. In the study of the determinants of cognitive change, it is especially important to store cognitive phenotypes and DNA from these participants because there are no equivalent data elsewhere that can provide actual cognitive change from youth. SMS1947 survivors, with their cognitive record from youth, would also provide informative participants for intervention studies to alleviate cognitive aging.

\section{Final Comments}

The data from the SMS are a national treasure, but they are also a disappearing archaeological resource, useful only as long as they can be applied to aspects of the participants later in life. To use them fully, to discover how differences in childhood psychometric intelligence weave into the rest of human life, we have a core research team that includes expertise in psychometrics, medicine, and epidemiology, with many collaborators for particular studies. Psychology's London School protagonists (Galton, 1883; Spearman, 1904, 1927; Burt, 1909-1910, 1940) consistently emphasized the importance of intelligence for many aspects of life. A broad consensus agrees with them up to a point (Neisser et al.,
1996), but presenting and understanding associations between psychometric intelligence and life's outcomes to a multidisciplinary audience are often controversial (Fischer et al., 1996; Herrnstein \& Murray, 1994). It is ironic that it is the legacy of Sir Godfrey Thomson, a London School antagonist, that is now providing multifaceted support for the impact of childhood psychometric intelligence on later life.

\section{References}

Anstey, K., \& Christensen, H. (2000). Education, activity, health, blood pressure and apolipoprotein $\mathrm{E}$ as predictors of cognitive change in old age: A review. Gerontology, 46, 163-177.

Anstey, K. J., \& Smith, G. A. (1999). Interrelationships among biological markers of aging, health, activity, acculturation, and cognitive performance in late adulthood. Psychology and Aging, 14, 605-618.

Arendt, T. (2001). Alzheimer's disease as a disorder of mechanisms underlying structural brain self-organization. Neuroscience, 102, 723765.

Baltes, P. B., \& Lindenberger, U. (1997). Emergence of a powerful connection between sensory and cognitive functioning across the adult life span: A new window to the study of cognitive aging? Psychology and Aging, 12, 12-21.

Bassey, E. J. (1998). Longitudinal changes in selected physical capabilities: Muscle strength, flexibility and body size. Age \& Ageing, 27(Suppl. 3), 12-16.

Bond, J., \& Carstairs, V. (1982). Services for the elderly: A survey of the characteristics and needs of a population of 5,000,000 old people (Scottish Home and Health Studies No. 42). Edinburgh, Scotland: Scottish Home and Health Department.

Breteler, M. M., Claus, J. J., Grobbee, D. E., \& Hoffman, A. (1994). Cardiovascular disease and distribution of cognitive function in elderly people: The Rotterdam Study. British Medical Journal, 308, 1605-1609.

Burt, C. (1909-1910). Experimental tests of general intelligence. British Journal of Psychology, 3, 94-177.

Burt, C. (1940). The factors of the mind. London: University of London Press.

Cauley, J. A., Zmuda, J. M., Yaffe, K., Kuller, L. H., Ferrell, R. E., Wisniewski, S. R., \& Cummings, S. R. (1999). Apolipoprotein E polymorphism: A new genetic marker of hip fracture risk. The study of osteoporotic fractures. Journal of Bone and Mineral Research, 14, $1175-1181$

Christensen, K., Vaupel, J. W., Holm, N. V., \& Yashin, A. I. (1995), Mortality among twins after age 6: Fetal origins hypothesis versus twin method. British Medical Journal, 310, 432-436.

Crawford, J. R., Deary, I. J., Starr, J., \& Whalley, L. J. (2001). The NART as an index of prior intellectual functioning: A retrospective validity study covering a 66 year interval. Psychological Medicine, 31, 451-458.

Davey Smith, G., Hart, C., Blane, D., \& Hole, D. (1998). Adverse socioeconomic conditions in childhood and cause specific adult mortality: Prospective observational study. British Medical Journal, 316, 16311635.

Davey Smith, G., Hart, C., Hole, D., et al. (1998). Education and occupational social class: Which is the more important indicator of mortality risk? Journal of Epidemiology and Community Health, 52, 153-160.

Davis, J. W., Ross, P. D., Preston, S. D., Nevitt, M. C., \& Wasnich, R. D. (1998). Strength, physical activity, and body mass index: Relationship to performance-based measures and activities of daily living among older Japanese women in Hawaii. Journal of the American Geriatrics Society, 46, 274-279.

Deary, I. J., Egan, V., Gibson, G. J., Brand, C. R., Austin, E., \& Kellaghan, T. (1996). Intelligence and the differentiation hypothesis. Intelligence, $23,105-132$

Deary, I. J., Leaper, S. A., Murray, A. D., Staff, R. T., \& Whalley, L. J. 
(2003). Cerebral white matter abnormalities and lifetime cognitive change: A 67-year follow-up of the Scottish Mental Survey of 1932. Psychology and Aging, 18, 140-148.

Deary, I. J., Starr, J. M., \& MacLennan, W. J. (1998). Fluid intelligence, memory and blood pressure in cognitive aging. Personality and Individual Differences, 25, 605-619.

Deary, I. J., Starr, J. M., \& MacLennan, W. J. (1999). Is age kinder to the initially more able? Differential aging of verbal ability in the HOPE study. Intelligence, 26, 357-375.

Deary, I. J., Whalley, L. J., Lemmon, H., Crawford, J. R., \& Starr, J. M. (2000). The stability of individual differences in mental ability from childhood to old age: Follow-up of the 1932 Scottish Mental Survey. Intelligence, 28, 49-55.

Deary, I. J., Whalley, L. J., \& Starr, J. M. (2003). IQ at age 11 and longevity: Results from a follow up of the Scottish Mental Survey 1932. In C. Finch, J.-M. Robine, \& Y. Christen (Eds.), Brain and longevity: Perspectives in longevity (pp. 153-164). Berlin: Springer.

Deary, I. J., Whalley, L. J., St. Clair, D., Breen, G., Leaper, S., Lemmon, H., et al. (2003). The influence of the epsilon 4 allele of the apolipoprotein $\mathrm{E}$ gene on childhood IQ, nonverbal reasoning in old age, and lifetime cognitive change. Intelligence, 31, 85-92.

Deary, I. J., Whiteman, M. C., Pattie, A., Starr, J. M., Hayward, C., Wright, A. F., et al. (2002). Cognitive change and the APOE epsilon4 allele. Nature, 418, 932

Detterman, D. K., \& Daniel, M. H. (1989). Correlations of mental tests with each other and with cognitive variables are highest for low IQ groups. Intelligence, 13, 349-359.

Dickens, W. T., \& Flynn, J. R. (2001). Heritability estimates versus large environmental effects: The IQ paradox resolved. Psychological Review, 108, 346-369.

Duthie, S. J., Whalley, L. J., Collins, A. R., Leaper, S., Berger, K., \& Deary, I. J. (2002). Homocysteine, B vitamin status and cognitive function in older adults. American Journal of Clinical Nutrition, 75, 908-913.

Fillit, H. M., Butler, R. N., O'Connell, A. W., Albert, M. S., Birren, J. E., Cotman, C. W., et al. (2002). Achieving and maintaining cognitive vitality with aging. Mayo Clinic Proceedings, 77, 681-696.

Fischer, C. S., Hout, M., Jankowski, M. S., Lucas, S. R., Swindler, A., \& Voss, K. (1996). Inequality by design: Cracking the bell curve myth. Princeton, NJ: Princeton University Press.

Flynn, J. R. (1999). Searching for justice: The discovery of IQ gains over time. American Psychologist, 54, 5-20.

Folstein, M. F., Folstein, S. E., \& McHugh, P. R. (1975). Mini-Mental State: A practical method for grading the cognitive state of patients for the clinician. Journal of Psychiatric Research, 12, 189-198.

Foy, J. M., \& Starr, J. M. (2000). Assessment and treatment of dementia in medical patients. Psychotherapy and Psychosomatics, 69, 59-69.

Fratiglioni, L., Grut, M., \& Forsell, Y. (1991). Prevalence of Alzheimer's disease and other dementias in an elderly urban population: Relationship with age, sex and education. Neurology, 41, 1886-1892.

Galton, F. (1883). Inquiries into human faculty. London: Dent.

Gill, T. M., Robison, J. T., \& Tinetti, M. E. (1997). Predictors of recovery in activities of daily living among disabled older persons living in the community. Journal of General Internal Medicine, 12, 757-762.

Gold, A. E., Deary, I. J., MacLeod, K. M., \& Frier, B. M. (1995). The effect of IQ level on the degree of cognitive deterioration experienced during acute hypoglycaemia in normal humans. Intelligence, 20, 267290

Guralnik, J. M., LaCroix, A. Z., Abbott, R. D., Berkman, L. F., Satterfield, S., Evans, D. A., \& Wallace, R. B. (1993). Maintaining mobility in late life. I. Demographic characteristics and chronic conditions. American Journal of Epidemiology, 137, 845-857.

Haan, M. N., Shemanski, L., Jagust, W. G., Manolio, T. A., \& Kuller, L. (1999). The role of APOE e4 in modulating effects of other risk factors for cognitive decline in elderly persons. Journal of the American Medical Association, 282, 40-46.

Hart, C. L., Taylor, M. D., Davey Smith, G., Whalley, L. J., Starr, J. M., Hole, D. J., et al. (2003). Childhood IQ, social class, deprivation and their relationships with mortality and morbidity risk in later life: Prospective observational study linking the Scottish Mental Survey 1932 and the Midspan studies. Psychosomatic Medicine, 65, 877-883.

Heasman, M. A., \& Clarke, J. A. (1979). Medical record linkage in Scotland. Health Bulletin, 37, 97-103.

Herrnstein, R. J., \& Murray, C. (1994). The bell curve. New York: Free Press.

Ho, S. C., Woo, J., Sham, A., Chan, S. G., \& Yu, A. L. M. (2001). A 3-year follow-up study of social, lifestyle and health predictors of cognitive impairment in a Chinese older cohort. International Journal of Epidemiology, 30, 1389-1396.

Jenkins, R., Fox, N. C., Rossor, A. M., Harvey, R. J., \& Rossor, M. N. (2000). Intracranial volume and Alzheimer disease: Evidence against the cerebral reserve hypothesis. Archives of Neurology, 57, 220-224.

Jensen, A. R. (1998). The $g$ factor: The science of mental ability. Westport, CT: Praeger Publishers.

Joint Workshop of the Research Unit of the Royal College of Physicians and the British Geriatrics Society. (1992). Standardized Assessment Scales for Elderly People. London: The Royal College of Physicians of London and the British Geriatrics Society.

Kangas, J., \& Bradway, K. (1971). Intelligence at middle age: A thirtyeight year follow-up. Developmental Psychology, 5, 333-337.

Katzman, R. (1993). Education and the prevalence of dementia and Alzheimer's disease. Neurology, 43, 13-20.

Kay, D., Beamish, P., \& Roth, M. (1964). Old age disorders in Newcastleupon-Tyne. British Journal of Psychiatry, 110, 146-158.

Korten, A. E., Jorm, A. F., Jiao, Z., Letenneeur, L., Jacomb, P. A., Henderson, A. S., et al. (1999). Health, cognitive and psychosocial factors as predictors of mortality in an elderly community sample. Journal of Epidemiology and Community Health, 53, 83-88.

Kunst, A. E., \& Mackenbach, J. P. (1994). The size of mortality differences associated with educational level in nine industrialized countries. American Journal of Public Health, 84, 932-937.

Lagerstrom, M., Bremme, K., Eneroth, P., \& Janson, C. G. (1994). Longterm development for girls and boys at age 16-18 as related to birth weight and gestational age. International Journal of Psychophysiology, 17, $175-180$.

LaRue, A., \& Jarvik, L. F. (1986). Cognitive function and prediction of dementia in old age. International Journal of Ageing and Human Development, $25,79-89$.

Leaper, S. A., Murray, A. D., Lemmon, H. A., Staff, R. T., Deary, I. J., Crawford, J. R., \& Whalley, L. J. (2001). Neuropsychological correlates of brain white matter lesions detected on MRI in the ABC1921 cohort. Radiology, 221, 51-55.

Legree, P. J., Pifer, M. E., \& Grafton, F. C. (1996). Correlations among cognitive abilities are lower for higher ability groups. Intelligence, 23 , 45-57.

Lezak, M. (1995). Neuropsychological testing. Oxford, England: Oxford University Press.

Lienert, G. A., \& Crott, H. W. (1964). Studies on the factor structure of intelligence in children, adolescents and adults. Vita Humana, 7, 147163.

MacIntyre, S. (1986). Health and illness. In B. Burgess (Ed.), Key variables in social investigation (pp. 76-98). London: Routledge \& Kegan Paul.

MacLullich, A. M. J., Seckl, J. R., Starr, J. M., \& Deary, I. J. (1998). The biology of intelligence: From association to mechanism. Intelligence, 26, 63-73.

MacMeeken, A. M. (1939). The intelligence of a representative group of Scottish children. London: University of London Press. 
MacPherson, J. S. (1958). Eleven-year-olds grow up. London: University of London Press.

Maxwell, J. (1961). The level and trend of national intelligence. London: University of London Press.

Maxwell, J. (1969). Sixteen years on: A follow-up of the 1947 Scottish Mental Survey. London: University of London Press.

McKinley, M. C., Strain, J. J., McPartlin, J., Scott, J. M., \& McNulty, H. (2001). Plasma homocysteine is not subject to seasonal variation. Clinical Chemistry, 47, 1430-1436.

Meinz, E. J., \& Salthouse, T. A. (1998). Is age kinder to females than to males? Psychonomic Bulletin and Review, 5, 56-70.

Morey, M. C., Pieper, C. F., \& Cornoni-Huntley, J. (1998). Physical fitness and functional limitations in community-dwelling older adults. Medicine \& Science in Sports \& Exercise, 30, 715-723.

Morgan, K. (1998). The Nottingham Longitudinal Study of Activity and Ageing: A methodological overview. Age \& Ageing, 27(Suppl. 3), 5-11.

Mori, E., Hirono, N., \& Yamashita, H. (1997). Premorbid brain size as a determinant of reserve capacity against intellectual decline in Alzheimer's disease. American Journal of Psychiatry, 154, 18-24.

National Institute of Aging Working Group on Aging and Genetic Epidemiology. (2001). Genetic epidemiologic studies on age-specified traits. American Journal of Epidemiology, 152, 1003-1008.

National Research Council. (2000). The aging mind: Opportunities in cognitive research. Washington, DC: National Academy Press.

Neale, R., Brayne, C., \& Johnson, A. L. (2001). Cognition and survival: An exploration in a large multicentre study of the population aged 65 years and over. International Journal of Epidemiology, 30, 1383-1388.

Neisser, U., Boodoo, G., Bouchard, T. J., Boykin, A. W., Brody, N., Ceci, S. J., et al. (1996). Intelligence: Knowns and unknowns. American Psychologist, 51, 77-101.

Nelson, H. E. (1982). National Adult Reading Test (NART) test manual (Part 1). Windsor, England: NFER-Nelson.

Nelson, H. E., \& Willison, J. R. (1991). National Adult Reading Test (NART) test manual (Part 2). Windsor, England: NFER-Nelson.

Owens, W. A. (1966). Age and mental abilities: A second adult follow-up. Journal of Educational Psychology, 57, 311-325.

Phillips, D. I., \& Barker, D. J. (1997). Association between low birthweight and high resting pulse in adult life: Is the sympathetic nervous system involved in programming the insulin resistance syndrome? Diabetic Medicine, 14, 673-677.

Plassman, B. L., Welsh, K. A., Helms, M., Brandt, J., Page, W. F., \& Breitner, J. C. S. (1995). Intelligence and education as predictors of cognitive state in late life: A 50-year follow-up. Neurology, 45, 14461450.

Pushkar Gold, D., Andres, D., Etezadi, J., Arbuckle, T., Schwartzman, A., \& Chaikelson, J. (1995). Structural equation model of intellectual change and continuity and predictors of intelligence in older men. Psychology and Aging, 10, 294-303.

Raven, J. C., Court, J. H., \& Raven, J. (1977). Manual for Raven's Progressive Matrices and Vocabulary Scales. London: H. K. Lewis.

Reynolds, M. D., Johnston, J. M., Dodge, H. H., DeKotsky, S. T., \& Ganguli, M. (1999). Small head size is related to low Mini-Mental State Examination scores in a community sample of non-demented older adults. Neurology, 53, 228-229.

Satz, P. (1993). Brain reserve capacity on symptom onset after brain injury: A formulation and review of evidence for threshold theory. Neuropsychology, 7, 273-295.

Schofield, P. W., Logroscino, G., Andrews, H. F., Albert, S., \& Stern, Y. (1997). An association between head circumference and Alzheimer's disease in a population-based study of aging and dementia. Neurology, 49, 30-37.

Schwartz, J. E., Friedman, H. S., Tucker, J. S., Tomlinson-Keasey, C., Wingard, D. L., \& Criqui, M. H. (1995). Sociodemographic and psy- chosocial factors in childhood as predictors of adult mortality? American Journal of Public Health, 85, 1237-1245.

Scottish Council for Research in Education. (1933). The intelligence of Scottish children: A national survey of an age-group. London: University of London Press.

Scottish Council for Research in Education. (1949). The trend of Scottish intelligence: A comparison of the 1947 and 1932 surveys of the intelligence of eleven-year-old pupils. London: University of London Press.

Scottish Council for Research in Education. (1958). Educational and other aspects of the 1947 Scottish Mental Survey. London: University of London Press.

Sharp, S. (1997). Much more at home with 3.999 pupils than with four: The contributions to psychometrics of Sir Godfrey Thomson. British Journal of Mathematical and Statistical Psychology, 50, 163-174.

Shenkin, S. D., Starr, J. M., Pattie, A., Rush, M. A., Whalley, L. J., \& Deary, I. J. (2001). Birth weight and cognitive function at age 11 years: The Scottish Mental Survey 1932. Archives of Diseases of Childhood, 85, 189-196.

Shetterly, S. M., Baxter, J., Morgenstern, N. E., Grigsby, J., \& Hamman, R. F. (1998). Higher instrumental activities of daily living disability in Hispanics compared with non-Hispanic whites in rural Colorado. The San Luis Valley Health and Aging Study. American Journal of Epidemiology, 147, 1019-1027.

Shiraki, M., Shiraki, Y., Aoki, C., Hosoi, T., Inoue, S., Kaneki, M., \& Ouchi, Y. (1997). Association of bone mineral density with apolipoprotein E phenotype. Journal of Bone and Mineral Research, 12, 1438 1445.

Snowdon, D. A., Greiner, L. H., Kemper, S. J., Nanayakkara, N., \& Mortimer, J. A. (1999). Linguistic ability in early life and longevity: Findings from the Nun Study. In J.-M. Robine, B. Forette, C. Franceschi, \& M. Allard (Eds.), The paradoxes of longevity: Perspectives in longevity (pp. 103-113). New York: Springer.

Snowdon, D. A., Kemper, S. J., Mortimer, J. A., Greiner, L. H., Wekstein D. R., \& Markesbery, W. R. (1996). Linguistic ability in early life and cognitive function and Alzheimer's disease in late life: Findings from the Nun Study. Journal of the American Medical Association, 275, $528-532$.

Snowdon, D. A., Ostwald, S. K., \& Kane, R. L. (1989). Education, survival, and independence in elderly Catholic sisters, 1936-1988. American Journal of Epidemiology, 130, 999-1012.

Sorensen, H. T., Sabroe, S., Olsen, J., Rothman, K. J., Gillman, M. W., \& Fischer, P. (1997). Birth weight and cognitive function in young adult life: Historical cohort study. British Medical Journal, 315, 401-403.

Spearman, C. (1904). "General intelligence," objectively determined and measured. American Journal of Psychology, 15, 201-293.

Spearman, C. (1927). The abilities of man. London: Macmillan.

Starr, J. M., Deary, I. J., Inch, S., Cross, S., \& MacLennan, W. J. (1997). Age-associated cognitive decline in healthy old people. Age and Ageing, 26, 295-300.

Starr, J. M., Deary, I. J., Lemmon, H., \& Whalley, L. J. (2000). Mental ability age 11 years and health status age 77 years. Age \& Ageing, 29, $253-258$.

Starr, J., Deary, I. J., \& Whalley, L. J. (1996). The effects of antihypertensive treatment on cognitive function: Results from the HOPE study. Journal of the American Geriatrics Society, 44, 411-415.

Starr, J. M., Whalley, L. J., Inch, S., \& Shering, P. A. (1992). The quantification of the relative effects of age and NART-predicted IQ on cognitive function in healthy old people. International Journal of Geriatric Psychiatry, 7, 153-157.

Stern, Y., Gurland, B., Tatermichi, T. K., Tang, M. X., Wilder, D., \& Mayeux, R. (1994). Influence of education and occupation on the incidence of Alzheimer's disease. Journal of the American Medical Association, 271, 1004-1010.

Taylor, M. D., Hart, C. L., Davey Smith, G., Starr, J. M., Hole, D. J., 
Whalley, L. J., et al. (2003). Childhood mental ability and smoking cessation in adulthood: Prospective observational study linking the Scottish Mental Survey 1932 and the Midspan studies. Journal of Epidemiology and Community Health, 57, 464-465.

Teasdale, T. W., Owen, D. R., \& Sorensen, T. I. (1991). Intelligence and educational level in adult males at the extremes of stature. Human Biology, 63, 19-30.

Thomson, G. H. (1939). The factorial analysis of human ability. London: University of London Press.

Townsend, P. (1979). Poverty in the United Kingdom. Harmondsworth, England: Penguin.

Vagero, D., \& Leon, D. (1994). Ischaemic heart disease and low birth weight: A test of the fetal-origins hypothesis from the Swedish Twin Study. Lancet, 343, 260-263.

Verhaar, H. J., Koele, J. J., Neijzen, T., Dessens, J. A., \& Duursma, S. A. (1998). Are arm span measurements useful in the prediction of osteoporosis in postmenopausal women? Osteoporosis International, 8, 174176

Wechsler, D. (1981). Wechsler Adult Intelligence Scale—Revised. New York: Psychological Corporation.

Wechsler, D. (1987). Wechsler Memory Scale—Revised. New York: Psychological Corporation.

Weinberg, W. A., Dietz, S. G., Penick, E. C., \& McAlister, W. H. (1974). Intelligence, reading achievement, physical size and social class. A study of St. Louis Caucasian boys aged 8-0 to 9-6 years, attending regular schools. Journal of Pediatrics, 85, 482-489.
Whalley, L. J., \& Deary, I. J. (2001). Longitudinal cohort study of childhood IQ and survival up to age 76. British Medical Journal, 322, $819-822$

Whalley, L. J., Starr, J. M., Athawes, R., Hunter, D., Pattie, A., \& Deary I. J. (2000). Childhood mental ability and dementia. Neurology, 55, $1455-1459$

Whalley L. J., Thomas, B. M., McGonigal, G., McQuade, C. A., Swingler, R., \& Black, R. (1995). Epidemiology of presenile Alzheimer's disease in Scotland (1974-1988): (1) Non-random geographical variation. British Journal of Psychiatry, 167, 728-731.

Whalley, L. J., Thomas, B. M., \& Starr, J. M. (1995). Epidemiology of presenile Alzheimer's disease in Scotland (1974-1988): (2) Exposures to possible risk factors. British Journal of Psychiatry, 167, 732-738.

Wood, R., \& Bain, M. (2001). The health and well-being of older people in Scotland. Edinburgh, Scotland: Common Services Agency for National Health Service Scotland, Information and Statistics Division.

Zigmond, A. S., \& Snaith, R. P. (1983). The Hospital Anxiety and Depression Scale. Acta Psychiatrica Scandinavica, 67, 361-370.

Zimmer, Z., Liu, X., Hermalin, A., \& Chuang, Y. L. (1998). Educational attainment and transitions in functional status among older Taiwanese. Demography, 35, 361-375.

Received February 19, 2002

Revision received September 23, 2002

Accepted October 22, 2002

\section{ORDER FORM}

\section{Start my 2004 subscription to Journal of Personality and Social Psychology! ISSN: 0022-3514}

$\$ 190.00$, APA Member/Affiliate
$\$ 382.00$, Individual Nonmember
$\$ 1,069.00$, InStitution
In DC add 5.75\% / In MD add 5\% sales tax
Total AMOUNT ENClOSED

Subscription orders must be prepaid. (Subscriptions are on a calendar year basis only.) Allow 4-6 weeks for delivery of the first issue. Call for international subscription rates.

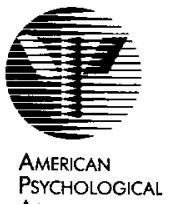

SEND THIS ORDER FORM TO:

American Psychological Association

Subscriptions

750 First Street, NE

Washington, DC 20002-4242

Or call (800) 374-2721, fax (202) 336-5568

TDD/TTY (202) 336-6123.

For subscription information, e-mail:

subscriptions@apa.org
Send me a FREE Sample Issue

Check enclosed (make payable to APA)

charge my: OvISA OMasterCard $\bigcirc$ American Express

Cardholder Name

Card No. Exp. Date

BILLING ADDRESS:

Signature (Required for Charge)

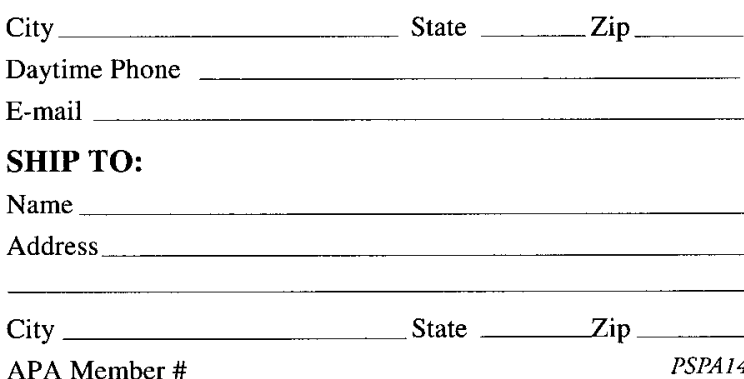

